\title{
Determinantes da Variação do Emprego dos Jovens Brasileiros: Uma Análise de Decomposição Estrutural para 2002-2015
}

\author{
Davi Winder Catelan ${ }^{1}$ (D) | Kênia Barreiro de Souza ${ }^{2}$ (D) | Vinícius de Almeida Vale ${ }^{3}$ \\ ${ }^{1}$ Programa de Pós-Graduação em Desenvolvimento Econômico, Universidade Federal do Paraná, Curitiba, PR, \\ Brasil. E-mail: daviwindercatelan.ecae@gmail.com \\ 2 Departamento de Economia e Programa de Pós-Graduação em Desenvolvimento Econômico, Universidade Federal \\ do Paraná, Curitiba, PR, Brasil. E-mail: keniadesouza@gmail.com \\ ${ }^{3}$ Departamento de Economia e Programa de Pós-Graduação em Desenvolvimento Econômico, Universidade Federal \\ do Paraná, Curitiba, PR, Brasil. E-mail: vinicius.a.vale@gmail.com
}

\begin{abstract}
RESUMO
Entre 2002 e 2015, o número de jovens ocupados diminuiu 19,98\%, enquanto o número de adultos ocupados aumentou $34,18 \%$. O descompasso entre essas duas taxas está relacionado a um conjunto de fatores como ciclo econômico, níveis de qualificação e decisões individuais de participação no mercado de trabalho. Além disso, variações na composição da demanda final e na utilização setorial de trabalho podem explicar a queda no emprego dos jovens, ponto vagamente explorado na literatura. Nesse contexto, o presente artigo examina as causas da variação do emprego dos jovens brasileiros utilizando uma Análise de Decomposição Estrutural. Para tanto, foram utilizadas as matrizes de insumo-produto estimadas a partir dos dados das Contas Nacionais e microdados da Pesquisa Nacional por Amostra de Domicílios para o período 2002-2015. Os resultados mostraram que os principais fatores explicativos da redução ocupacional de jovens no período foram a queda na participação relativa dos jovens, o aumento na produtividade geral do trabalho e a redução no grau de utilização da mão de obra juvenil. Por outro lado, os componentes da demanda final contribuíram positivamente para a variação do emprego desse grupo. O avanço no consumo das famílias foi responsável pela maior parte da criação de empregos para os jovens, seguido, em importância, por investimento, exportações e consumo do governo.
\end{abstract}

PALAVRAS-CHAVE

Jovens, Mercado de trabalho, Análise de Decomposição Estrutural, Insumo-produto

Determinants of Brazilian Youth Employment Variation: A Structural Decomposition Analysis for 2002-2015

\begin{abstract}
Between 2002 and 2015, the number of young people participating in the labor market fell by 19.98\% while the number of employed adults increased by $34.18 \%$. The mismatch between these two rates is related to a set of factors such as the economic cycle, qualification levels, and individual decisions to participate in the labor market. In addition, variations in the final demand composition and in the sectoral labor use may explain the drop in youth employment, a point that is barely explored in the literature. In this context, this paper examines the causes of the variation in employment of young Brazilians using a Structural Decomposition Analysis. For this purpose, we used input-output matrices estimated from the National Accounts data and microdata from the National Household Sample Survey for the period 2002-2015. The results showed that the main explanatory factors for the occupational reduction of young people in the period were the decrease in the relative participation of young people in total employment, the increase in the overall sectoral labor productivity, and the reduction in the degree of labor utilization of the youth employment. On the other hand, the components of the final demand contributed positively to the variation in employment of this group. The increase in household consumption was responsible for most of the jobs creation for young people, followed in importance by investment, exports, and government consumption.
\end{abstract}

KEYWORDS

Youth, Labor market, Structural Decomposition Analysis, Input-output

CLASSIFICAÇ̃̃O JEL

C67, J13, J21 


\section{Introdução}

O mercado de trabalho brasileiro vivenciou uma fase de prosperidade durante a primeira década dos anos 2000 e início da segunda, caracterizada pela elevação dos níveis salariais e de emprego (Corseuil e Foguel, 2012; Dedecca e Lopreato, 2013). Esse cenário favorável esteve relacionado, inicialmente, a uma trajetória de maior crescimento econômico e distribuição de renda. A partir da crise financeira internacional, em 2008, os indicadores de trabalho passaram a apresentar uma melhora menos expressiva, especialmente entre 2009 e 2014 (Souen e Campos, 2017). Com o início de uma recessão doméstica, em meados de 2015, houve uma piora generalizada das variáveis ocupacionais, com aumento do desemprego, redução dos rendimentos e precarização do trabalho (Pochmann, 2018).

Nesse contexto, os movimentos do emprego estiveram, em certa medida, relacionados à trajetória da economia. Apesar disso, a literatura aponta que o mercado de trabalho não reage de forma homogênea às flutuações econômicas e, portanto, alguns grupos de individuos, como mulheres, jovens e negros, tendem a ser mais impactados (Cho e Newhouse, 2013). Em especial, os jovens se destacam como um grupo para o qual os efeitos cíclicos da economia não têm um impacto claro sobre a dinâmica ocupacional (Garcia et al., 2012). Enquanto o PIB brasileiro e a população em idade ativa (PIA) cresceram, respectivamente, 45,38\% e 22,33\% entre 2002 e 2015 (IBGE, 2020a), o número de jovens ocupados recuou cerca de $20 \%$ no mesmo período, passando de 18,27 milhões de trabalhadores para 14,62 milhões, conforme informações da PNAD (IBGE, 2020b). O número de adultos ocupados, por sua vez, saltou 33,4\% no período, aumentando de 57,2 milhões para 76,75 milhões $^{1}$.

Esse descompasso entre as taxas de crescimento de jovens e de adultos ocupados está relacionado a vários fatores, como ciclo econômico, níveis de qualificação e decisões individuais de participação no mercado de trabalho. O número de jovens que participa da força de trabalho, por exemplo, caiu 14,61\% entre 2002 e 2015, enquanto o de adultos cresceu 34,18\% (IBGE, 2020b).

O menor crescimento do emprego entre os jovens também está relacionado à maior probabilidade de desemprego desse grupo. Há na literatura estudos que apontam as flutuações da demanda agregada como fatores explicativos (Clark e Summers, 1978; Korenman e Neumark, 2000; O'Higgins, 2001; Bayrak e Tatli, 2018) e outros que consideram o papel das características produtivas individuais desses trabalhadores, como educação e experiência (Freeman, 1979; Clark e Summers, 1982; Leighton e Mincer, 1982). Os salários relativos também são frequentemente apontados como possiveis determinantes do desemprego juvenil (Rice, 1986; O’Higgins, 2001), bem como fatores demográficos do mercado laboral, como a proporção de jovens no mercado de trabalho (Freeman e Wise, 1982; Jimeno e Rodriguez-Palenzuela, 2002; Biavaschi et al., 2012; Tomić, 2018). Há também estudos que enfatizam o papel das instituições na

\footnotetext{
${ }^{1} \mathrm{O}$ grupo de jovens engloba os trabalhadores com idade entre 14 e 24 anos e o de adultos entre 25 e 64 anos de idade.
} 
determinação do desemprego juvenil (Biavaschi et al., 2012; O’Higgins, 2012; Bertola et al., 2013; Tomić, 2018).

No caso do Brasil, grande parte dos estudos enfatiza as características individuais dos trabalhadores. Em suma, a literatura mostra que a elevada incidência e a duração do desemprego juvenil estão relacionadas à baixa qualificação e experiência e à maior rotatividade no emprego, em comparação aos trabalhadores mais velhos (Flori, 2005; Cunha et al., 2011; Corseuil et al., 2013; Araújo e Antigo, 2016; Pontes et al., 2018). Entretanto, não foram encontrados trabalhos na literatura nacional que exploram a questão sob a ótica das relações intersetoriais da economia.

Nesse sentido, este trabalho tem como objetivo avaliar as variações do emprego dos jovens brasileiros entre 2002 e 2015 a partir das interdependências setoriais da economia brasileira. Para tal, realizar-se-á a decomposição da variação do emprego em fatores relacionados às mudanças no mercado de trabalho, na demanda final e na tecnologia a partir da Análise de Decomposição Estrutural (Structural Decomposition Analysis - SDA) com as matrizes de insumo-produto (MIPs) provenientes do Sistema de Contas Nacionais (SCN) e dados da Pesquisa Nacional por Amostra de Domicílios (PNAD).

Dessa maneira, este trabalho contribui para a literatura ao explorar os determinantes do emprego juvenil a partir das relações econômicas intersetoriais da economia brasileira entre 2002 e 2015 . Vale ressaltar que outros estudos da literatura brasileira utilizaram o método SDA para investigar os movimentos do emprego agregado (Kupfer e Freitas, 2004; Sesso Filho et al., 2010), bem como do emprego na indústria (Nakatani-Macedo et al., 2015).

Além disso, o presente estudo contribui ao identificar os setores e os fatores mais relevantes na variação do emprego juvenil, o que pode auxiliar no direcionamento de políticas voltadas ao mercado de trabalho, principalmente políticas de primeiro emprego. O elevado desemprego juvenil é um fenômeno que tende a agravar os problemas socioeconômicos do país a médio e longo prazos e, portanto, as políticas públicas devem ser formuladas considerando-se as particularidades desse grupo no mercado de trabalho. Evidências mostram que a incidência do desemprego entre tais trabalhadores pode, no longo prazo, desestimular a busca por trabalho, fazendo com que muitos desses indivíduos não estudem e nem trabalhem (Artner, 2013). Esses efeitos, por sua vez, podem aumentar a marginalização da juventude brasileira, com repercussões em outras dimensões do desenvolvimento social. Como argumentam Silva e Kassouf (2002), períodos prolongados de desemprego entre os jovens podem aumentar o consumo de drogas e bebidas alcoólicas, a violência, a prostituição e a gravidez precoce. Além disso, o desemprego juvenil pode comprometer o sistema previdenciário dada a diminuição da parcela da população que trabalha e contribui para o sistema de previdência social, concomitante ao aumento da parcela de aposentados (Van der Gaag e Beer, 2015), como é o caso do Brasil. 
Além desta introdução, o estudo está dividido em mais quatro seções. A segunda seção apresenta uma revisão de literatura sobre os determinantes da evolução do desemprego juvenil. A base de dados e a metodologia adotada são abordadas na seção posterior. A quarta seção apresenta e discute os resultados. Por fim, a quinta seção traz as considerações finais.

\section{Os jovens no mercado de trabalho}

O alto desemprego de jovens é uma questão amplamente debatida na literatura, uma vez que suas consequências são múltiplas e, normalmente, piores em países em desenvolvimento como o Brasil. Em suma, pode-se destacar cinco fatores que explicam o desemprego entre jovens: (i) flutuações na demanda agregada; (ii) salários relativos; (iii) proporção de jovens no mercado de trabalho; (iv) fatores institucionais; e (v) características produtivas individuais.

No primeiro caso, a maior vulnerabilidade juvenil frente às flutuações da demanda agregada é verificada em países de diferentes níveis de renda. Pelo lado da demanda de trabalho, isso se deve, em parte, à segregação ocupacional e ao grau de exposição dos segmentos em que os jovens são representativos. Esses trabalhadores tendem a estar inseridos nos setores mais cíclicos, como na construção civil, o que ajuda a explicar por que suas taxas de desemprego variam tanto em resposta às mudanças das condições econômicas (Hoynes et al., 2012; Bredemeier e Winklerp, 2017).

Pelo lado da oferta, evidências empíricas sugerem que nos países em desenvolvimento é comum, em meio a uma crise econômica, os jovens deixarem de se qualificar para ingressarem na força de trabalho (Fallon e Lucas, 2002), caso verificado para o Brasil no período entre 1982 e 1999 (Duryea et al., 2007), mas não verificado durante a crise econômica do biênio 2015/2016 (Corseuil et al., 2020). Já nas nações desenvolvidas, esses indivíduos tendem a se afastar do mercado laboral durante períodos de recessão para se qualificarem (Barakat et al., 2010).

Durante as crises econômicas da década de 1990 e a crise econômica internacional de 2008, houve substancial elevação do desemprego juvenil em relação às demais faixas etárias nos países europeus e nos EUA, conforme verificam Verick (2009), Barakat et al. (2010), Choudhry et al. (2012) e Hoynes et al. (2012). Esse mesmo movimento ocorreu em países de renda média, como destacado por Choudhry et al. (2012) e Cho e Newhouse (2013). No caso dos países europeus, a crise econômica de 2008 marcou a reversão de uma tendência de queda no desemprego de jovens que ocorria há anos (Dietrich, 2013; Banerji et al., 2014; Incera, 2017). Esse ponto de inflexão também se verificou para os EUA, o Japão (Bell e Blanchflower, 2011) e para a América Latina (Anyanwu, 2013). Bayrak e Tatli (2018) também atestaram a existência de uma relação negativa entre crescimento econômico e desemprego juvenil para 31 países da OCDE entre os anos de 2000 e 2015.

No caso do Brasil, durante os anos de 1980 e 1990, a combinação de crises exter- 
nas e redução do crescimento econômico resultou em um aumento no desemprego de jovens em uma proporção superior à verificada para os indivíduos mais velhos (Justesen, 2008; Santos e Gimenez, 2015). Durante a primeira década dos anos 2000, por sua vez, o maior crescimento econômico brasileiro teve impactos positivos sobre a taxa de ocupação desses trabalhadores, havendo, paralelamente, uma redução na participação desse grupo na força de trabalho (Baltar e Leone, 2015; Santos e Gimenez, 2015). Corseuil et al. (2020) analisaram o mercado de trabalho brasileiro entre 2012 e 2019 e identificaram um forte aumento na taxa de desocupação juvenil durante a crise econômica de 2015 e 2016. Como a taxa de participação desse grupo se manteve em queda em quase todo o período, o aumento na taxa de desocupação foi atribuído à queda na ocupação.

Vale destacar que a tendência de redução na taxa de participação juvenil no mercado de trabalho brasileiro entre o final dos anos 1990 e o início dos anos 2010 refletiu o expressivo aumento na oferta de vagas na educação básica e no ensino superior no país, bem como o crescimento da renda das famílias brasileiras. A ampliação do acesso ao ensino superior foi favorecida pelo lançamento ou expansão de programas sociais durante os governos Lula e Dilma. Entre esses programas, destacam-se aqueles com ênfase na ampliação do acesso de jovens ao ensino universitário ou técnico, como o Fundo de Financiamento Estudantil (FIES), o Programa Universidade para Todos (Prouni) e o Programa Nacional de Acesso ao Ensino Técnico e Emprego (Pronatec). Além disso, houve um considerável aumento na renda das famílias mais pobres em função de programas sociais, como o Bolsa Família e o Minha Casa, Minha Vida, e pelo aumento real no salário mínimo. Esses avanços, segundo Santos e Gimenez (2015), permitiram uma redução no trabalho infantil e juvenil no período.

O segundo fator que explica as variações do desemprego dos trabalhadores jovens se refere aos salários relativos. A teoria econômica tradicional argumenta que, ceteris paribus, aumentos relativos nos salários de indivíduos mais jovens têm um impacto negativo no nível de emprego. Isso se fundamenta na hipótese de que os dois grupos são fatores produtivos tidos como substitutos próximos, o que muitas vezes não se verifica, principalmente em relação aos adultos altamente qualificados e mais experientes (O’Higgins, 2001). Se jovens e adultos forem complementares no mercado de trabalho, refletindo diferentes características produtivas, os salários relativos terão pouca ou nenhuma influência na determinação do desemprego juvenil (O'Higgins, 2001). Pelo lado da oferta de trabalho, espera-se que o aumento dos salários dos jovens os incentive a entrar na força de trabalho (Anyanwu, 2013).

Alguns estudos sugerem que há poucos indícios de substitutibilidade entre os dois grupos. Blanchflower e Freeman (1996) observam que, durante os anos de 1980 e 1990, os salários relativos dos jovens tiveram um papel pouco relevante na determinação do emprego desse grupo nos países da OCDE. Bell e Blanchflower (2011) chegam à mesma conclusão ao avaliarem os EUA e o Reino Unido no final da década de 1990 e na primeira década dos anos 2000. Resultados díspares são encontrados 
por Rice (1986), que identifica um papel relevante dos salários relativos para explicar o aumento do desemprego juvenil no Reino Unido durante os anos de 1960 e 1970.

O terceiro fator que contribui para o desemprego juvenil é a proporção de jovens no mercado de trabalho, isto é, a estrutura etária da população (Freeman e Wise, 1982; O'Higgins, 2001; Biavaschi et al., 2012; Tomić, 2018). Conforme Shimer (1998), quando um grupo de indivíduos de determinada faixa etária aumenta sua participação no mercado laboral, sua taxa de desemprego aumenta em relação à taxa agregada. Alguns estudos confirmam a importância desse fator na explicação do desemprego dos jovens. Jimeno e Rodriguez-Palenzuela (2002), por exemplo, atestam isso para dezenove países da OCDE entre 1960 e 1990. Já Korenman e Neumark (2000) concluem que, embora esse componente tenha tido algum efeito explicativo sobre o desemprego juvenil em países da OCDE entre 1970 e 1990, as condições agregadas do mercado de trabalho tiveram uma influência maior. Tomić (2018), por sua vez, analisou os países da União Europeia entre os anos 2002 e 2014 e verificou que o aumento na idade média da população exerceu um impacto negativo sobre o desemprego de jovens, principalmente nos países com menores taxas de desemprego juvenil.

Vale ressaltar que os países em desenvolvimento sofrem mais com esse problema devido ao padrão de evolução demográfica (com taxas de fecundidade elevadas) e ao decorrente aumento da presença de jovens no mercado (Freeman e Wise, 1982; O'Higgins, 2001). No Oriente Médio e no norte da África, uma demanda limitada de mão de obra juvenil, somada a uma oferta crescente, agravou o desemprego desses trabalhadores entre meados dos anos 1970 e a década de 2010 (Biavaschi et al., 2012). O mesmo foi verificado por Durotoye (2014) para o México, a Turquia e a Indonésia, onde o forte crescimento demográfico e a migração das populações rurais para o meio urbano nas últimas décadas levaram a um crescimento da força de trabalho de jovens em uma proporção maior do que a capacidade de absorção da economia.

Mais recentemente, alguns estudos têm enfatizado o papel das instituições na determinação do desemprego juvenil. Em especial, essa literatura investiga o papel do salário mínimo e do grau de flexibilização do mercado de trabalho como fatores explicativos (Biavaschi et al., 2012; O’Higgins, 2012; Bertola et al., 2013; Tomić, 2018). De acordo com Biavaschi et al. (2012), o processo de transição dos jovens da escola para o mercado de trabalho é fortemente influenciado por esses fatores institucionais. Muitos países contam com uma legislação de proteção ao emprego para ocupações com contratos permanentes e uma regulamentação mais flexivel para empregos temporários. Se, por um lado, a rígida proteção contra demissões tende a aumentar o desemprego juvenil, por outro, a existência de um segmento de empregos flexíveis oferece a oportunidade de entrada no mercado de trabalho para os jovens, com possibilidade de transição para o segmento de empregos permanentes (O’Higgins, 2012; Biavaschi et al., 2012; Tomić, 2018).

Analisando os países europeus entre 2002 e 2012, Bertola et al. (2013) verificaram que a desregulamentação do emprego promovida em alguns países antes de crise de 
2008 teve impactos variados no desemprego de jovens durante e após a crise. A Alemanha se caracterizou por uma rápida recuperação do emprego juvenil, enquanto a Itália e a Espanha permaneceram com altas taxas de desemprego para esse grupo. Tomić (2018), por sua vez, mostrou que a flexibilidade da legislação laboral, representada pela participação de contratos temporários, esteve associada a taxas de desemprego mais baixas nos países europeus entre 2002 e 2014.

Outros trabalhos investigaram os impactos do salário mínimo no desemprego juvenil. No entanto, novamente, os resultados não são consensuais. Há estudos que verificam que aumentos no salário mínimo tiveram impactos negativos no emprego dos jovens nos países desenvolvidos (Gorry, 2013; Laporšek, 2013), enquanto outros sugerem poucas evidências desse efeito (Sturn, 2017), inclusive para o Brasil (Broecke e Vandeweyer, 2016) ${ }^{2}$.

Por fim, o alto desemprego juvenil está relacionado às características produtivas individuais desse grupo, como os baixos níveis de qualificação e experiência e a alta rotatividade. Em geral, os jovens pouco qualificados estão desproporcionalmente expostos ao desemprego devido, por um lado, à incompatibilidade entre o conhecimento adquirido e às habilidades exigidas pelo mercado (Choudhry et al., 2012) e, por outro, devido à escolha dos próprios jovens em não aceitar as ocupações disponíveis (Freeman, 1979). Nesse sentido, as aspirações ocupacionais de alguns desses indivíduos os fazem optar pelo desemprego por se considerarem qualificados demais para determinadas ocupações.

Quanto à alta rotatividade, pela ótica da demanda de trabalho, esta pode ser atribuída, em parte, à existência de empregos temporários uma vez que, quando os contratos expiram, alguns indivíduos ficam desempregados enquanto procuram por novas ocupações (Freeman, 1979). Pelo lado da oferta, os jovens exibem altas taxas de mobilidade ao trocarem frequentemente de emprego em busca de um trabalho satisfatório (Freeman, 1979; Clark e Summers, 1982). Ademais, os jovens carecem de outro componente do capital humano, a experiência (Clark e Summers, 1982; Leighton e Mincer, 1982; Araújo e Antigo, 2016). Esse problema, contudo, é amenizado à medida que esses indivíduos se inserem no mercado de trabalho e diminuem seu gap de experiência.

Para o Brasil, há evidências de que o baixo capital humano entre os jovens tem raízes históricas, contribuindo para que esses apresentem uma taxa de desemprego mais elevada do que os demais grupos. Alguns estudos mostraram que, entre a última

\footnotetext{
${ }^{2}$ Gorry (2013) estima que os aumentos do salário mínimo nos EUA, entre 2007 e 2009, aumentaram o desemprego juvenil. Além disso, o autor mostra que uma redução do salário mínimo na França resultaria em quedas no desemprego para os trabalhadores jovens. Laporšek (2013) chega a conclusões similares ao encontrar um impacto negativo e estatisticamente significativo do salário mínimo no emprego de jovens para a União Europeia entre 1996 e 2011. Broecke e Vandeweyer (2016), por sua vez, usam dados da Pesquisa Mensal do Emprego (PME) para o Brasil, entre os anos de 2003 e 2014, e concluem que o salário mínimo têm um impacto marginal nos resultados do emprego de jovens. Sturn (2017) também encontra poucas evidências de que o salário mínimo afetou o desemprego juvenil em 19 países da OCDE, entre 1983 e 2013.
} 
década dos anos 1990 e a primeira dos anos 2000, a alta rotatividade no trabalho, acompanhada do baixo nível de qualificação e da falta de experiência, contribuiu para elevar a incidência e a duração do desemprego juvenil (Flori, 2005; Cunha et al., 2011; Corseuil et al., 2013). O mesmo foi constatado por Araújo e Antigo (2016) para o período entre 2002 e 2011. Nesse caso, os autores verificaram que os jovens em situação de desemprego apresentavam menor probabilidade de conseguir emprego do que os trabalhadores adultos, principalmente os jovens com menor qualificação.

Assim, a literatura que trata dos determinantes do desemprego juvenil tem resultado em um número considerável de estudos. As diferentes explicações sugerem que não há um diagnóstico consensual. Ademais, a maior parte desses trabalhos não examina o assunto sob o ângulo das relações intersetoriais da economia. Como argumenta Incera (2017), tal abordagem permite avaliar aspectos relacionados à demanda de mão de obra. Para o Brasil, especificamente, não foram encontrados estudos que avaliam o assunto recorrendo ao método de decomposição estrutural. Dessa maneira, o presente estudo busca contribuir para essa literatura.

\section{Procedimentos metodológicos}

\subsection{Decomposição padrão do emprego}

O método de decomposição estrutural (SDA - Structural Decomposition Analysis) teve sua origem no trabalho seminal de Carter (1970), com contribuições significativas de Blair e Wyckoff (1989) e Skolka (1989). Em suma, o método permite decompor a mudança total na produção em quaisquer dois pontos no tempo dadas as mudanças técnicas dos setores e na demanda final (Vale e Perobelli, 2020). Além disso, vários estudos estenderam o método para decompor variáveis que dependem do produto, como valor adicionado, emprego, renda e emissões ${ }^{3}$.

No caso do Brasil, por exemplo, alguns estudos utilizaram a metodologia para verificar os fatores explicativos da variação do emprego agregado no país (Kupfer e Freitas, 2004; Sesso Filho et al., 2010), bem como do emprego na indústria (Nakatani-Macedo et al., 2015). No presente estudo, por sua vez, utiliza-se o método SDA para examinar as causas das mudanças no emprego dos jovens brasileiros, tendo como base a estratégia adotada por Incera $(2017)^{4}$.

Para tal, parte-se da equação básica de insumo-produto, dada por:

\footnotetext{
${ }^{3}$ Ver Miller e Blair (2009) para mais detalhes e exemplos de decomposições de variáveis que dependem do produto.

${ }^{4}$ Tal método se fundamenta em Han (1995), que analisa a evolução do emprego, considerando outras variáveis demográficas ou de ocupação, e decompõe os coeficientes de emprego em efeitos setoriais de ocupação e em efeitos de produtividade. Entretanto, vale ressaltar que a solução de uma SDA aditiva não é única e depende do tamanho dos termos de interação. Mais detalhes estão disponiveis em Dietzenbacher e Los (1998), Arto e Dietzenbacher (2014) e Miller e Blair (2009).
} 


$$
x=(I-A)^{-1} y
$$

em que $x$ é o vetor de produção setorial; $I$ é a matriz identidade; $A$ é a matriz de coeficientes técnicos de insumo-produto (proporção de insumos por unidade de produto); e $y$ é o vetor de demanda final. Considerando que $(I-A)^{-1}$ representa a matriz inversa de Leontief $(L)$ com os requerimentos totais (diretos e indiretos) de insumos, a Equação (1) pode ser reescrita como:

$$
x=L y
$$

Além disso, para avaliar as mudanças no emprego dos jovens, determina-se, inicialmente, o emprego setorial dos jovens, em termos de full time equivalent (FTE) ${ }^{5}$, a partir da seguinte equação:

$$
e_{y}=H(I-A)^{-1} y
$$

em que $e_{y}$ é o vetor com os empregos FTE de jovens por setor; $H$ é uma matriz diagonal com os coeficientes de emprego FTE de jovens, dados pelo número de empregos de jovens FTE em cada setor dividido pela produção bruta desse mesmo setor.

Considerando $L=(I-A)^{-1}$, a Equação (3) pode ser reescrita como:

$$
e_{y}=H L y
$$

Assumindo tal relação, a variação do emprego de jovens, em termos de FTE, entre dois anos ( $t$ e $t-1)$, é dada por:

$$
\Delta e_{y}=H_{t} L_{t} y_{t}-H_{t-1} L_{t-1} y_{t-1}
$$

Após algumas manipulações algébricas, a Equação (5) pode ser reescrita da seguinte maneira:

\footnotetext{
${ }^{5}$ O emprego FTE é um parâmetro que mede o número de horas efetivamente trabalhadas pelos indivíduos durante determinado período. Para calcular essa variável, dividiu-se o total de horas trabalhadas na semana pela média semanal de horas trabalhadas em empregos de tempo integral, isto é, 40 horas, no caso do Brasil.
} 


$$
\begin{aligned}
\Delta e_{y} & =\left(H_{t} L_{t}-H_{t-1} L_{t-1}\right) y_{t-1}+H_{t-1} L_{t-1}\left(y_{t}-y_{t-1}\right) \\
& +\left(H_{t} L_{t}-H_{t-1} L_{t-1}\right)\left(y_{t}-y_{t-1}\right)
\end{aligned}
$$

em que $\left(H_{t} L_{t}-H_{t-1} L_{t-1}\right) y_{t-1}$ representa o efeito das mudanças tecnológicas nos coeficientes de emprego; $H_{t-1} L_{t-1}\left(y_{t}-y_{t-1}\right)$ mede o efeito das mudanças na demanda; e $\left(H_{t} L_{t}-H_{t-1} L_{t-1}\right)\left(y_{t}-y_{t-1}\right)$ mede o efeito da interação entre os dois fatores.

Cabe ressaltar que o primeiro termo, $\left(H_{t} L_{t}-H_{t-1} L_{t-1}\right) y_{t-1}$, inclui o efeito direto das mudanças tecnológicas nos coeficientes de emprego dadas as alterações nos coeficientes diretos de emprego $(\Delta H)$; e o efeito indireto das mudanças tecnológicas nos coeficientes de emprego dadas as alterações na matriz inversa de Leontief $(\Delta L)$, ou seja, nos requerimentos diretos e indiretos.

A parcela referente às mudanças tecnológicas pode ser decomposta da seguinte maneira:

$$
\begin{aligned}
& \left(H_{t} L_{t}-H_{t-1} L_{t-1}\right) y_{t-1}=\left(H_{t} L_{t}-H_{t-1} L_{t}+H_{t-1} L_{t}-H_{t-1} L_{t-1}\right) y_{t-1} \\
& \left(H_{t} L_{t}-H_{t-1} L_{t-1}\right) y_{t-1}=\left(H_{t}-H_{t-1}\right) L_{t} y_{t-1}+H_{t-1}\left(L_{t}-L_{t-1}\right) y_{t-1}
\end{aligned}
$$

$$
\begin{aligned}
\left(H_{t} L_{t}-H_{t-1} L_{t-1}\right) y_{t-1} & =\left(H_{t}-H_{t-1}\right) L_{t} y_{t-1} \\
& -\left(H_{t}-H_{t-1}\right) L_{t-1} y_{t-1} \\
& +\left(H_{t}-H_{t-1}\right) L_{t-1} y_{t-1} \\
& +H_{t-1}\left(L_{t}-L_{t-1}\right) y_{t-1}
\end{aligned}
$$

$$
\begin{aligned}
\left(H_{t} L_{t}-H_{t-1} L_{t-1}\right) y_{t-1} & =\left(H_{t}-H_{t-1}\right) L_{t-1} y_{t-1}+H_{t-1}\left(L_{t}-L_{t-1}\right) y_{t-1} \\
& +\left(H_{t}-H_{t-1}\right)\left(L_{t}-L_{t-1}\right) y_{t-1}
\end{aligned}
$$

em que $\left(H_{t}-H_{t-1}\right) L_{t-1} y_{t-1}$ mede as mudanças nos coeficientes de emprego; $H_{t-1}\left(L_{t}-\right.$ $\left.L_{t-1}\right) y_{t-1}$ mede as mudanças nos insumos intermediários; e $\left(H_{t}-H_{t-1}\right)\left(L_{t}-L_{t-1}\right) y_{t-1}$ mede a interação entre as mudanças nos dois fatores. 


\subsection{Decomposição dos coeficientes de emprego}

De acordo com Incera (2017), além da decomposição padrão, pode-se decompor as mudanças nos coeficientes de emprego $(\Delta H)$ em uma parcela referente às mudanças no grau de utilização do trabalho juvenil e em outra referente às mudanças na produtividade do trabalho desse grupo, ambas por setor. Definindo-se $l_{i}^{y}$ como o total de empregos de jovens no setor $i$, tem-se:

$$
H=\frac{l_{i}^{y i n t}}{x_{i}}=\frac{l_{i}^{y i n t}}{l_{i}^{y}} \frac{l_{i}^{y}}{x_{i}}=H^{u} H^{p}
$$

em que $l_{i}^{\text {yint }}$ é o total de empregos FTE de jovens no setor $i$ e o termo $H^{u}=l_{i}^{y i n t} / l_{i}^{y}$ captura o grau de utilização do trabalho juvenil. O termo $H^{p}=l_{i}^{y} / x_{i}$ é o inverso da produtividade dos trabalhadores jovens inseridos no setor $\mathrm{i}$, uma vez que é dado pela razão entre o total de empregos de jovens $\left(l_{i}^{y}\right)$ e o total produzido no respectivo setor $\left(x_{i}\right)$. Então, quanto mais próximo de um estiverem os coeficientes de $H^{u}$, maior é a proporção de jovens em ocupações em tempo integral. Por outro lado, quando os coeficientes de $H^{u}$ tomam o valor de 0,5 , ou menos, maior é a proporção desse grupo em ocupações em tempo parcial.

Tendo estabelecido essas relações, adota-se um procedimento similar ao aplicado às Equações (7)-(10) para decompor as mudanças nos coeficientes de emprego:

$$
\begin{aligned}
\left(H_{t}-H_{t-1}\right) L_{t-1} y_{t-1}= & \left(H_{t}^{u} H_{t}^{p}-H_{t-1}^{u} H_{t-1}^{p}\right) L_{t-1} y_{t-1} \\
\left(H_{t}-H_{t-1}\right) L_{t-1} y_{t-1}=\left(H_{t}^{u} H_{t}^{p}\right. & \left.+H_{t-1}^{u} H_{t}^{p}-H_{t-1}^{u} H_{t}^{p}-H_{t-1}^{u} H_{t-1}^{p}\right) L_{t-1} y_{t-1} \\
& \\
& =\left(H_{t}^{u}-H_{t-1}^{u}\right) H_{t}^{p} L_{t-1} y_{t-1} \\
& +H_{t-1}^{u}\left(H_{t}^{p}-H_{t-1}^{p}\right) L_{t-1} y_{t-1} \\
\left(H_{t}-H_{t-1}\right) L_{t-1} y_{t-1} & \\
& \\
& =\left(H_{t}^{u}-H_{t-1}^{u}\right) H_{t}^{p} L_{t-1} y_{t-1} \\
& -\left(H_{t}^{u}-H_{t-1}^{u}\right) H_{t-1}^{p} L_{t-1} y_{t-1} \\
& +\left(H_{t}^{u}-H_{t-1}^{u}\right) H_{t-1}^{p} L_{t-1} y_{t-1} \\
& +H_{t-1}^{u}\left(H_{t}^{p}-H_{t-1}^{p}\right) L_{t-1} y_{t-1}
\end{aligned}
$$




$$
\begin{aligned}
\left(H_{t}-H_{t-1}\right) L_{t-1} y_{t-1} & =\left(H_{t}^{u}-H_{t-1}^{u}\right) H_{t-1}^{p} L_{t-1} y_{t-1} \\
& +H_{t-1}^{u}\left(H_{t}^{p}-H_{t-1}^{p}\right) L_{t-1} y_{t-1} \\
& +\left(H_{t}^{u}-H_{t-1}^{u}\right)\left(H_{t}^{p}-H_{t-1}^{p}\right) L_{t-1} y_{t-1}
\end{aligned}
$$

em que $\Delta H^{u}=\left(H_{t}^{u}-H_{t-1}^{u}\right) H_{t-1}^{p} L_{t-1} y_{t-1}$ mede mudanças no grau de utilização da mão de obra juvenil; $\Delta H^{p}=H_{t-1}^{u}\left(H_{t}^{p}-H_{t-1}^{p}\right) L_{t-1} y_{t-1}$ mede mudanças na produtividade do trabalho dos jovens; e $\left(H_{t}^{u}-H_{t-1}^{u}\right)\left(H_{t}^{p}-H_{t-1}^{p}\right) L_{t-1} y_{t-1}$ mede a interação entre as mudanças nos dois fatores.

Quanto à matriz $H^{p}$, uma decomposição adicional é feita para incorporar outros dois fatores. O primeiro é a participação relativa dos jovens no emprego total para cada setor $\left(H^{s}\right)$. O outro fator é a produtividade setorial do trabalho $\left(H^{r}\right)$. Estabelecendo $l_{i}^{t}$ como o total de empregos no setor $i$, tem-se:

$$
H^{p}=\frac{l_{i}^{y}}{x_{i}}=\frac{l_{i}^{y}}{l_{i}^{t}} \frac{l_{i}^{t}}{x_{i}}=H^{s} H^{r}
$$

Seguindo o mesmo procedimento adotado nas Equações (12) a (15), obtém-se:

$$
\begin{aligned}
\Delta H^{p} & =H_{t-1}^{u}\left(H_{t}^{s}-H_{t-1}^{s}\right) H_{t-1}^{r} L_{t-1} y_{t-1}+H_{t-1}^{u} H_{t-1}^{s}\left(H_{t}^{r}-H_{t-1}^{r}\right) L_{t-1} y_{t-1} \\
& +H_{t-1}^{u}\left(H_{t}^{s}-H_{t-1}^{s}\right)\left(H_{t}^{r}-H_{t-1}^{r}\right) L_{t-1} y_{t-1}
\end{aligned}
$$

em que $\Delta H^{s}=H_{t-1}^{u}\left(H_{t}^{s}-H_{t-1}^{s}\right) H_{t-1}^{r} L_{t-1} y_{t-1}$ mede as mudanças na participação relativa dos jovens; $\Delta H^{r}=H_{t-1}^{u} H_{t-1}^{s}\left(H_{t}^{r}-H_{t-1}^{r}\right) L_{t-1} y_{t-1}$ mede as mudanças na produtividade do trabalho; e $H_{t-1}^{u}\left(H_{t}^{s}-H_{t-1}^{s}\right)\left(H_{t}^{r}-H_{t-1}^{r}\right) L_{t-1} y_{t-1}$ mede a interação entre as mudanças nos dois fatores.

\subsection{Decomposição da demanda final}

Por último, é possivel decompor o vetor de demanda final em seus principais componentes:

$$
\begin{aligned}
\Delta y & =H_{t-1} L_{t-1}\left(y_{t}-y_{t-1}\right) \\
\Delta y & =H_{t-1} L_{t-1}\left(y_{t}^{c}-y_{t-1}^{c}\right)+H_{t-1} L_{t-1}\left(y_{t}^{g}-y_{t-1}^{g}\right) \\
& +H_{t-1} L_{t-1}\left(y_{t}^{i}-y_{t-1}^{i}\right)+H_{t-1} L_{t-1}\left(y_{t}^{e}-y_{t-1}^{e}\right)
\end{aligned}
$$


em que $\Delta y^{c}=H_{t-1} L_{t-1}\left(y_{t}^{c}-y_{t-1}^{c}\right)$ mede as mudanças no consumo final das famílias; $\Delta y^{g}=H_{t-1} L_{t-1}\left(y_{t}^{g}-y_{t-1}^{g}\right)$ mede as mudanças no consumo do governo; $\Delta y^{i}=$ $H_{t-1} L_{t-1}\left(y_{t}^{i}-y_{t-1}^{i}\right)$ mede as mudanças no investimento; e $\Delta y^{e}=H_{t-1} L_{t-1}\left(y_{t}^{e}-y_{t-1}^{e}\right)$ mede as mudanças nas exportações.

Em suma, a variação no emprego de jovens, em termos de FTE, é decomposta como segue:

$$
\begin{aligned}
\Delta e_{y} & =\underbrace{\left(H_{t}^{u}-H_{t-1}^{u}\right) H_{t-1}^{p} L_{t-1} y_{t-1}}_{1}+\underbrace{H_{t-1}^{u}\left(H_{t}^{s}-H_{t-1}^{s}\right) H_{t-1}^{r} L_{t-1} y_{t-1}}_{2} \\
& +\underbrace{H_{t-1}^{u} H_{t-1}^{s}\left(H_{t}^{r}-H_{t-1}^{r}\right) L_{t-1} y_{t-1}}_{2} \\
& +\underbrace{H_{t-1}^{u}\left(H_{t}^{s}-H_{t-1}^{s}\right)\left(H_{t}^{r}-H_{t-1}^{r}\right) L_{t-1} y_{t-1}}_{3} \\
& +\underbrace{\left(H_{t}^{u}-H_{t-1}^{u}\right)\left(H_{t}^{p}-H_{t-1}^{p}\right) L_{t-1} y_{t-1}+\underbrace{H_{t-1}\left(L_{t}-L_{t-1}\right) y_{t-1}}_{5}}_{5} \\
& +\underbrace{\left.H_{t-1} H_{t-1}\right)\left(L_{t}-L_{t-1}\right) y_{t-1}}_{9}+\underbrace{H_{t-1} L_{t-1}\left(y_{t}^{c}-y_{t-1}^{c}\right)}_{7-1} \\
& +\underbrace{H_{t-1} L_{t-1}\left(y_{t}^{e}-y_{t-1}^{e}\right)}_{8}+\underbrace{H_{t-1} L_{t-1}\left(y_{t}^{i}-y_{t-1}^{i}\right)}_{11}+\underbrace{\left(H_{t} L_{t}-H_{t-1} L_{t-1}\right)\left(y_{t}-y_{t-1}\right)}_{10}
\end{aligned}
$$

As doze parcelas se referem, respectivamente: (1) às mudanças no grau de utilização da mão de obra juvenil; (2) às mudanças na participação relativa dos jovens no emprego total; (3) às mudanças na produtividade do trabalho; (4) à interação entre as mudanças na participação relativa dos jovens e a produtividade do trabalho; (5) à interação entre as mudanças no grau de utilização da mão de obra juvenil e a produtividade do trabalho desse grupo; (6) às mudanças nos insumos intermediários; (7) à interação entre as mudanças nos coeficiente de emprego e os insumos intermediários; (8) às mudanças no consumo das famílias; (9) às mudanças no consumo do governo; (10) às mudanças no investimento; (11) às mudanças nas exportações; e (12) à interação entre as mudanças tecnológicas e a demanda final.

\section{Base de dados}

Para decomposição das variações do emprego dos jovens na economia brasileira entre 2002 e 2015, este trabalho utilizou matrizes de insumo-produto estimadas para o período. Para estimação das matrizes de insumo-produto, aplicou-se a metodologia de Guilhoto e Sesso Filho (2005, 2010), a série retropolada das Tabelas de Recursos e Usos (TRUs) do Sistema de Contas Nacionais (SCN) disponibilizada pelo Instituto Brasileiro de Geografia e Estatística (IBGE), abrangendo 51 atividades e 107 produtos. 
O uso da série retropolada é feito para preservar a comparabilidade dos dados ao longo do tempo visto as mudanças conceituais e de classificação adotadas a partir de 2010, no âmbito do SCN - Brasil - referência $2010^{6}$.

Os dados de emprego de jovens foram obtidos a partir da PNAD (IBGE, 2020b) e das matrizes de insumo-produto. Primeiramente, foram calculadas as proporções de trabalhadores jovens no total de trabalhadores ocupados em cada setor com os microdados da PNAD. Em seguida, essas proporções foram aplicadas ao total de empregos setoriais da matriz de insumo-produto, o que permitiu o detalhamento setorial do número de empregos de jovens e de adultos. Entretanto, como os setores da PNAD não se encaixam perfeitamente aos do SCN, os setores foram agregados em 46 atividades, conforme apresentado no Quadro Al do Apêndice.

O grupo de jovens engloba os indivíduos com idade entre 14 e 24 anos. O emprego total de jovens por setor foi calculado em termos de full time equivalent (FTE), conforme sugerido por Incera (2017) e descrito na metodologia. Para os jovens, esse procedimento é particularmente importante uma vez que muitos deles não se dedicam exclusivamente ao trabalho, fazendo com que suas jornadas tenham duração variável. Assim, o FTE é uma maneira de normalizar essas jornadas ao longo do tempo.

Também foram calculadas as mudanças no número de jovens que participam do mercado de trabalho e no número de jovens desocupados, ambos em termos de FTE. A estimação desses indicadores foi feita a partir dos dados da PNAD, calibrados de acordo com as informações das matrizes de insumo-produto ${ }^{7}$. Essas variáveis são apresentadas na Tabela A1 do Apêndice.

É importante ressaltar que a aplicação da decomposição estrutural requer que todos os dados monetários estejam em uma unidade padrão para que os resultados possam ser comparados ao longo do tempo, excluindo desvios provocados pelas mudanças nos preços. Como neste estudo a decomposição é empregada para variações de emprego entre dois anos sucessivos para todo o período, foram usadas as matrizes a preços correntes para o ano base e as matrizes a preços do ano base para o ano seguinte. Portanto, a partir das TRUs a preços correntes e a preços do ano anterior, foram estimadas matrizes de insumo-produto a preços correntes e a preços do ano anterior para cada ano por meio do método de Guilhoto e Sesso Filho (2005, 2010). Então, se, por exemplo, a decomposição é aplicada para a variação de empregos entre 2002 e 2003, utiliza-se para 2002 a matriz de insumo-produto a preços correntes e para 2003 a matriz a preços do ano de 2002.

\footnotetext{
${ }^{6}$ Detalhes da retropolação de séries e Tabelas de Recursos e Usos do SCN do Brasil estão disponíveis em IBGE (2015).

${ }^{7}$ Para a mensuração do número de jovens desocupados e do número de jovens que participam do mercado de trabalho, ambos em FTE, calculou-se a razão entre o número de jovens desocupados e o número de jovens ocupados em FTE a partir da PNAD. Em seguida, essa razão foi multiplicada pelo número de postos de trabalho de jovens em FTE obtido por meio das matrizes de insumo-produto, resultando no número de jovens desocupados em FTE. A soma dessas duas últimas variáveis resultou no número de jovens que participam do mercado de trabalho em FTE.
} 


\section{Resultados}

A base de dados utilizada permite observar as transformações ocorridas no mercado de trabalho brasileiro nas décadas de 2000 e 2010. O primeiro período foi marcado pelo crescimento da atividade econômica e, consequentemente, pela geração de empregos. Porém, a partir de 2015, em um contexto de recessão econômica, houve piora nos indicadores do mercado de trabalho brasileiro. Nesse sentido, com base nas informações da PNAD, a Figura 1 apresenta as variações na taxa de participação e na taxa de desocupação de jovens e adultos no mercado de trabalho brasileiro entre 2002 e $2015^{8}$.

Figura 1. Variações nas taxas de participação e de desocupação de jovens e adultos, Brasil, 2002-2015 (em \%)

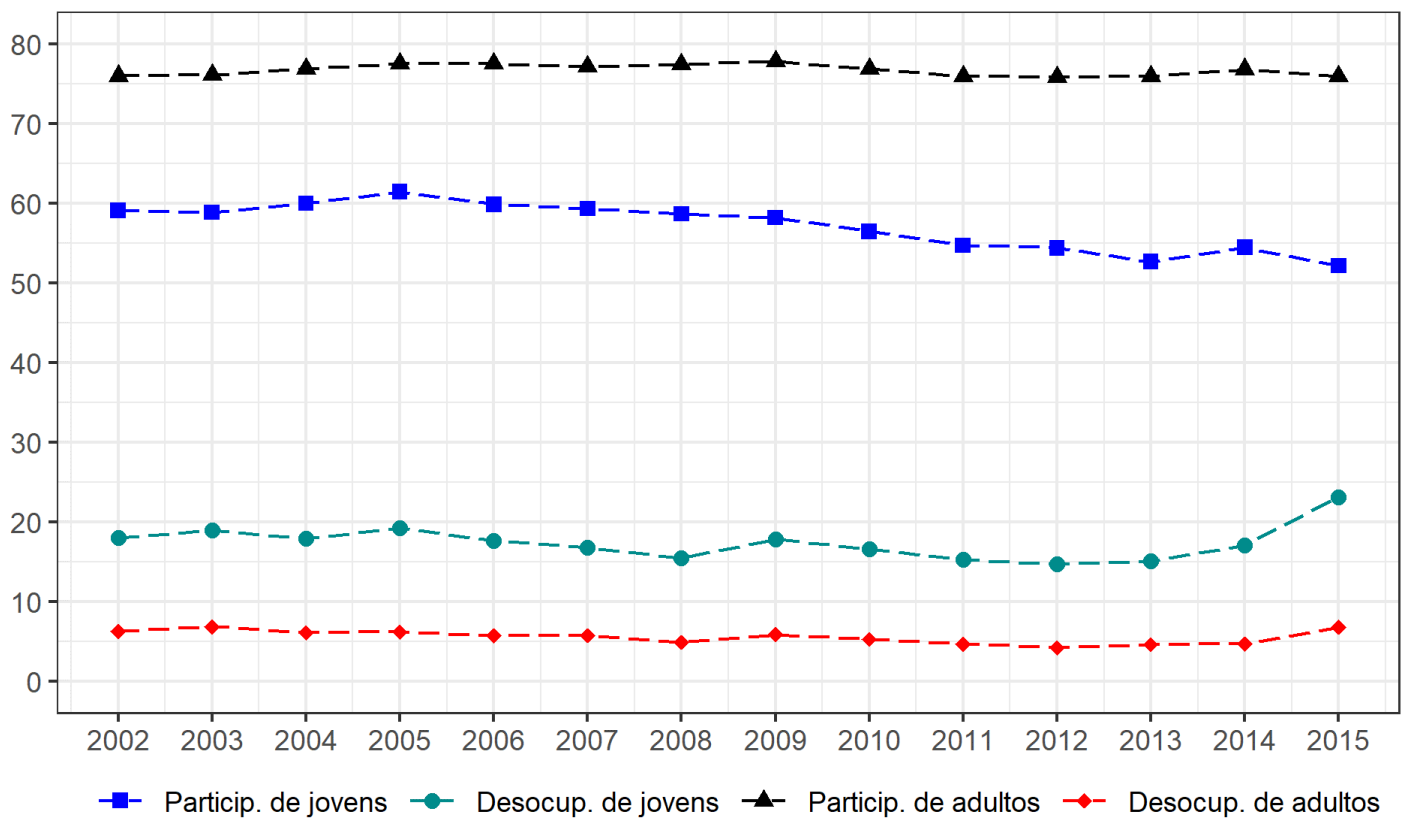

Fonte: Elaboração dos autores a partir da PNAD (IBGE, 2020b).

A taxa de participação dos trabalhadores adultos (Particip. de adultos) aumentou continuamente entre 2002 e 2009, passando de 75,97\% para 77,81\%. A partir de 2010, a variação na participação desse grupo se tornou negativa, chegando ao patamar de 75,80\% em 2012. Após dois anos de crescimento, entre 2013 e 2014, esse indicador recuou de 76,92\% em 2014 para 75,91\% em 2015. Já a taxa de participação dos jovens (Particip. de jovens) declinou em quase todos os anos analisados, passando de 59,06\% em 2002 para 52,16\% em 2015, o que pode estar relacionado à escolha desses indivíduos em obter maiores níveis de qualificação, postergando sua entrada na força de trabalho (Pontes et al., 2018). Os únicos movimentos de alta na

\footnotetext{
${ }^{8} \mathrm{~A}$ taxa de desocupação representa a proporção de pessoas desocupadas em relação à força de trabalho, enquanto a taxa de participação representa a proporção de pessoas na força de trabalho em relação às pessoas em idade de trabalhar.
} 
participação desse grupo ocorreram entre 2003 e 2005 e em 2014 . O ano de 2015 registrou o maior recuo na participação juvenil no período, com uma queda de 2,28 p.p., sugerindo que, em períodos de crise econômica, os jovens que estão desempregados optam por deixar de procurar emprego, provocando uma queda na taxa de participação. Consequentemente, a diferença nas taxas de participação de jovens e adultos aumentou no período analisado.

A taxa de desocupação dos adultos (Desocup. de adultos) declinou de 6,31\% em 2002 para 4,92\% em 2008. Após um crescimento de 0,98 p.p. em 2009, essa taxa voltou a cair entre 2010 e 2012 , mantendo-se relativamente estável até 2014 . No ano de 2015, a desocupação desses trabalhadores cresceu 2,12 p.p., passando de $4,71 \%$ em 2014 para 6,83\% em 2015. No caso dos jovens, a taxa de desocupação (Desocup. de jovens) caiu de 17,98\% em 2002 para 14,69\% em 2012, sendo este o menor nível da série. Contudo, entre 2013 e 2015, esse indicador apresentou trajetória ascendente, alcançando o nível de 23,14\% em 2015. Os dados indicam que o grupo de jovens, além de apresentar níveis relativamente elevados de desemprego, tende a ser mais afetado pelo ciclo econômico, uma vez que durante as crises econômicas de 2009 e 2015 ocorreram os maiores aumentos na desocupação juvenil, indicando maior vulnerabilidade dos jovens frente às flutuações da demanda agregada, conforme indicado pela literatura (O’Higgins, 2001; Hoynes et al., 2012; Bredemeier e Winklerp, 2017).

A partir das informações das matrizes de insumo-produto e da PNAD, a Figura 2 apresenta as variações no número de postos de trabalho de jovens em FTE, no número de postos de trabalho de adultos e no número total de postos de trabalho para o Brasil entre 2002 e 2015. Nota-se que os movimentos do emprego agregado e dos indivíduos adultos estiveram, em certa medida, relacionados à trajetória do movimento geral da economia no período, quando o PIB brasileiro teve um crescimento de $45,38 \%$. O emprego total teve um crescimento de $23,71 \%$, passando de 82,42 milhões de vagas para 101,69 milhões, e o emprego dos indivíduos adultos aumentou 36,58\%, saindo de 62,89 milhões para 85,89 milhões. O único movimento de baixa para essas categorias ocorreu em 2015, quando o PIB brasileiro recuou 3,8\% e os empregos geral e de adultos caíram $4,27 \%$ e $2,24 \%$, respectivamente.

Por sua vez, o emprego dos jovens, em termos de FTE, diminuiu 22,67\%, passando de 18,92 milhões de vagas em 2002 para 14,63 milhões em 2015. A pior variação ocorreu em 2015, quando cerca de 2,22 milhões de postos de trabalho foram perdidos. Tal resultado sugere que a crise econômica agravou uma tendência de queda que já vinha ocorrendo. A única exceção ocorreu entre 2003 e 2005, quando o emprego desses indivíduos cresceu 4,08\%, atingindo o pico de 19,42 milhões de postos de trabalho em 2005. Novamente, os dados corroboram que os impactos das flutuações econômicas tendem a atingir os jovens de modo distinto, conforme indicado pela literatura (Garcia et al., 2012; Cho e Newhouse, 2013). 
Figura 2. Variação no número de postos de trabalho e do PIB, Brasil, 2002-2015 $(2002=100)$

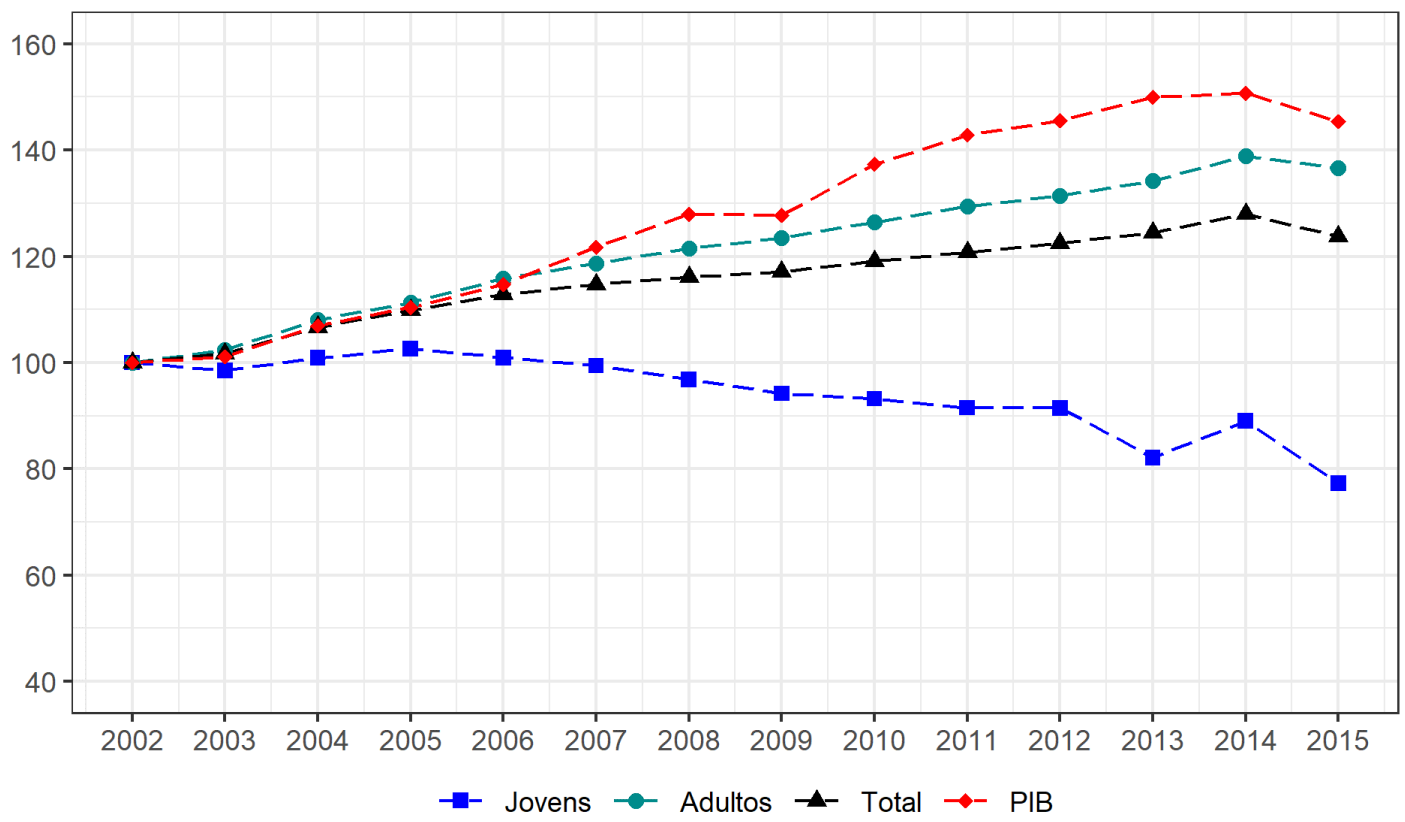

Fonte: Elaboração dos autores a partir da PNAD (IBGE, 2020b) e do SCN (IBGE, 2020a).

Quanto às mudanças de participação setorial ocorridas entre 2002 e 2015, a Figura 3 sintetiza essa evolução dividindo o total de trabalhadores entre os treze setores de atividade mais representativos para os jovens. Esses setores são Agricultura, silvicultura e exploração florestal (AGR), Pecuária e pesca (PEC), Alimentos e bebidas (ALI), Artigos do vestuário e acessórios (VES), Construção civil (CON), Comércio (COM), Transporte, armazenagem e correio (TRA), Serviços de alojamento e alimentação (ALO), Serviços prestados às empresas (EMP), Educação mercantil (EDU), Serviços prestados às famílias (FAM), Serviços domésticos (DOM) e Administração pública e seguridade social (ADM). Somados, os setores corresponderam a cerca de $88,17 \%$ da ocupação total de jovens no período. Os 33 setores restantes foram agrupados em Outros.

Um primeiro fato que chama atenção é a concentração de postos de trabalho no Comércio (COM), com 26,59\% do total, seguido, em importância, pela Agricultura, silvicultura e exploração florestal (AGR), com 7,74\%, e pela Construção civil (COM), com 7,47\%. Nota-se, também, a baixa participação desse grupo em setores manufatureiros, como Alimentos e bebidas (ALI) e Artigos do vestuário e acessórios (VES), que corresponderam a menos de $5 \%$ da ocupação total de jovens no período. Os Serviços domésticos (DOM), a Agricultura (AGR) e a Pecuária (PEC) foram os setores que mais perderam representatividade, com recuos de 5,70 p.p., 4,71 p.p. e 4,04 p.p., respectivamente. Já os setores de Comércio (COM) e Construção civil (COM) foram os que mais ganharam participação, com aumentos de 5,02 p.p. e de 2,16 p.p., respectivamente. 
Figura 3. Evolução da estrutura setorial da ocupação de jovens nos setores de atividade em porcentagem do total, Brasil, 2002-2015

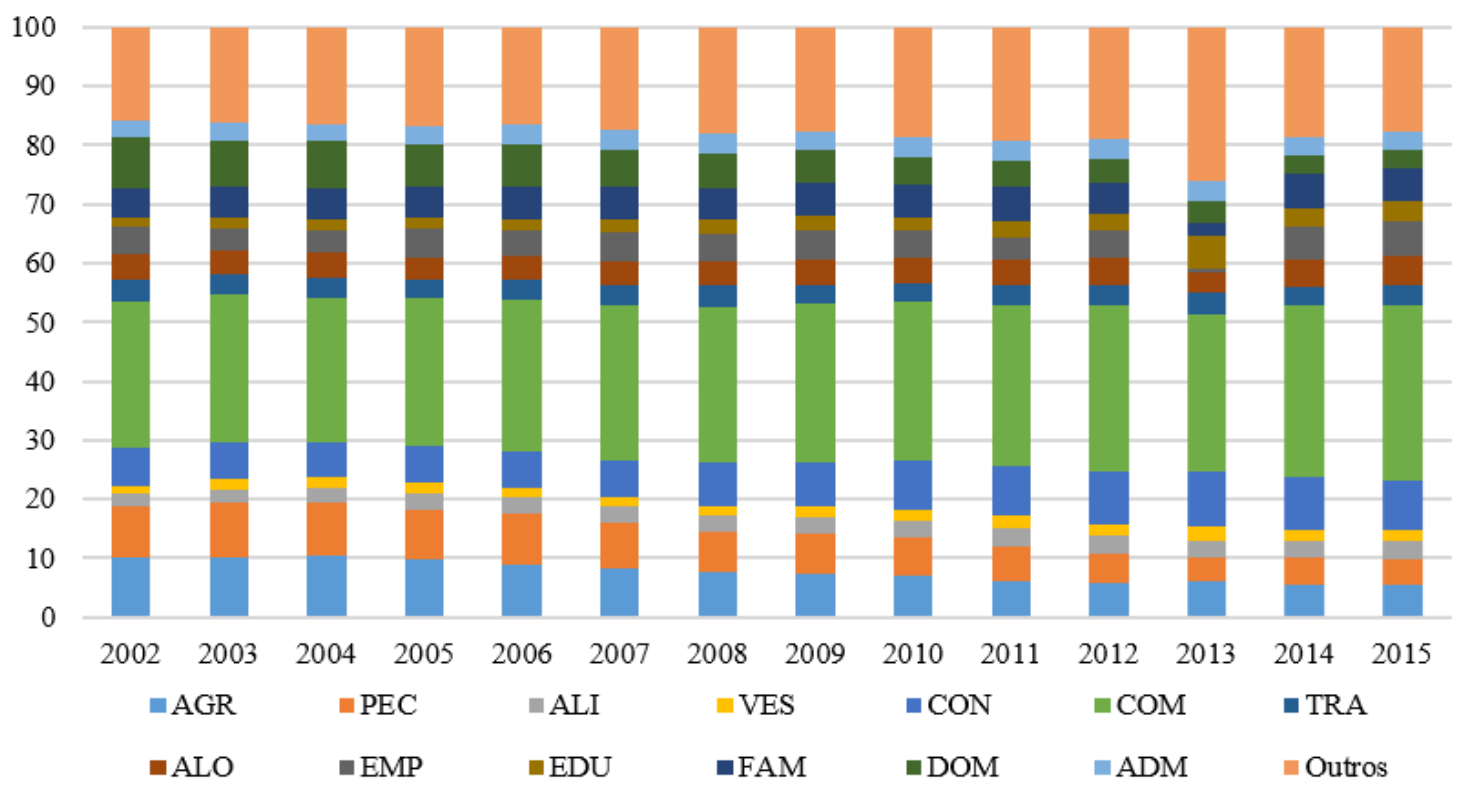

Fonte: Elaboração dos autores a partir da PNAD (IBGE, 2020b) e do SCN (IBGE, 2020a).

Esses resultados mostram, como esperado, a sobrerrepresentação de setores entre os jovens que, normalmente, concentram empregos de baixas remuneração e qualificação. Os empregos no comércio, por exemplo, costumam remunerar menos do que os da indústria (Corseuil e Franca, 2015). Ademais, o comércio é marcado por uma alta incidência de vagas de trabalho temporárias, o que contribui para a alta rotatividade desses trabalhadores. Já agricultura, pecuária, serviços domésticos e construção civil se destacam como segmentos com alta incidência de ocupações informais e mão de obra pouco qualificada (IBGE, 2018).

A partir dos dados e da Análise de Decomposição Estrutural, foi possivel decompor os fatores que explicam a variação do emprego dos jovens, conforme a Tabela 1. Como indicado, houve no período uma redução de $22,7 \%$ do emprego desses trabalhadores, uma queda de 4,30 milhões de postos de trabalho. Os resultados da decomposição estrutural para o período 2002-2015 mostram que o principal determinante foi o componente referente às mudanças na participação relativa dos jovens no emprego total ( $\Delta$ Participação relativa), respondendo pela queda de $6.887,07$ mil postos de trabalho ou $160,29 \%$ da redução total.

Por um lado, a redução na participação relativa dos jovens no mercado de trabalho pode estar relacionada a variações na demanda de trabalho. Nesse caso, é possivel que em determinadas ocupações os empregadores tenham substituído esses indivíduos por trabalhadores mais velhos, cujos níveis de qualificação e experiência são maiores. Por outro lado, a perda de participação juvenil também pode ser explicada por variações na oferta de trabalho. Como discutido, os avanços no acesso à educação 
e o crescimento na renda das famílias brasileiras tendem a fazer com que uma parcela crescente de jovens postergue sua entrada no mercado de trabalho.

Os aumentos na produtividade do trabalho ( $\Delta$ Produtividade do trabalho), definida como a razão entre o total produzido e o total de empregos de jovens nos setores, reduziram o emprego desse grupo em cerca de 2.900,03 mil postos de trabalho, o que representa $67,50 \%$ do declínio absoluto. A evolução desse índice descreve as variações no emprego relacionadas, exclusivamente, às mudanças na demanda total de mão de obra, mantendo as demais variáveis constantes. O fato de esse componente ser negativo revela que a produtividade geral do emprego aumentou e, portanto, reduziu a demanda por esse insumo, uma vez que uma quantidade menor de trabalho passou a ser requerida para cada unidade de produção. As exceções ao sinal negativo do fator de produtividade ocorreram nos anos de 2003, 2009, 2014 e 2015, ou seja, nos anos de pior desempenho da atividade econômica brasileira no período. Em particular, nos anos de 2009 e 2015, a queda do PIB foi maior do que a redução do emprego juvenil, explicando a queda na produtividade do emprego.

Campos et al. (2017) sugerem que os principais fatores que explicam a variação da produtividade do trabalho são as mudanças na qualificação dos trabalhadores, na tecnologia, nas instituições e na rotatividade ocupacional ${ }^{9}$. Dado que a rotatividade ocupacional aumentou no Brasil no período analisado, os ganhos de produtividade podem ser atribuídos à maior qualificação dos trabalhadores e ao progresso tecnológico em certos setores. Ademais, ocorreram importantes avanços institucionais que podem ter elevado a produtividade, uma vez que resultaram em melhorias nas relações de trabalho. Nesse caso, destacam-se a maior formalização no emprego, o papel dos sindicatos e a ampliação dos mecanismos de proteção ao emprego (Campos et al., 2017).

As mudanças no grau de utilização da mão de obra juvenil ( $\Delta$ Utilização do trabalho) explicaram 30,76\% do recuo do emprego dos jovens entre 2002 e 2015, correspondendo a uma redução de 1.321,53 mil postos de trabalho. Como essa variável representa o número de horas efetivamente trabalhadas pelos trabalhadores jovens, o resultado indica um aumento na proporção de empregos mantidos em meio período.

Quanto à demanda final, as mudanças nos seus componentes contribuíram positivamente para a variação do emprego juvenil, pois, durante a maior parte do período, esses componentes cresceram, impactando na geração de empregos para esse grupo. Em especial, o consumo das famílias ( $\Delta$ Consumo das famílias) foi responsável pela geração de 4.886,24 mil postos de trabalho para os jovens. Sua importância relativa pode ser atribuída à sua maior representatividade no valor total da demanda final, equivalendo a $51,96 \%$, e ao seu crescimento médio de $3,82 \%$ ao ano. Com exceção dos anos de 2003 e 2015, o consumo das famílias brasileiras cresceu em todo o período influenciado por fatores como a valorização real do salário-mínimo, o cresci-

\footnotetext{
${ }^{9}$ Os autores analisam a produtividade do trabalho no Brasil entre o final da década de 1990 e início da década de 2010.
} 
mento de programas sociais, a expansão do crédito e a formalização do emprego em um contexto de inflação baixa (Giambiagi et al., 2016). Como grande parte dos jovens brasileiros está inserida no comércio e serviços, a elevação do consumo beneficiou esses segmentos e aumentou a necessidade de contratação dessa mão de obra.

As variações no investimento ( $\Delta$ Investimento) e nas exportações ( $\Delta$ Exportações) também se destacaram como fatores relevantes para a geração de postos de trabalho para o grupo em questão. As mudanças nos dois componentes permitiram um crescimento de 1.294,34 mil e de 1.154,67 mil empregos, respectivamente. Enquanto o investimento representou $16,37 \%$ do valor da demanda final no período e teve um crescimento médio anual de 3,45\%, as exportações corresponderam a 12,92\% e cresceram $4,16 \%$ a.a. O crescimento das exportações teve um papel importante para a geração de empregos de jovens principalmente entre 2002 e 2007. Nesse período, houve um crescimento anual de mais de 9\% nas exportações brasileiras motivado pelo forte crescimento econômico mundial, principalmente da China. Esse cenário permitiu a expansão dos preços internacionais das commodities, beneficiando países como o Brasil (Giambiagi et al., 2016).

Por último, o consumo do governo ( $\Delta$ Consumo do governo) contribuiu para a criação de 662,85 mil empregos em período integral para jovens. Apesar de ser o segundo elemento mais representativo da demanda final, com 18,75\% do valor total, e ter apresentado um crescimento similar aos demais $(3,12 \%)$, sua capacidade em gerar empregos para os jovens foi menor. A possivel explicação foi a baixa representatividade de jovens nos setores mais propensos a se beneficiar dos gastos do governo, como saúde pública e educação pública.

No que concerne à variação nos insumos intermediários ( $\Delta$ Insumos intermediários), essa teve uma contribuição pouco expressiva, reduzindo o emprego dos jovens em cerca de 270,99 mil vagas, o que equivale a 6,31\% da variação total. Isso ocorre porque as mudanças tecnológicas tendem a ser lentas e dificilmente capturadas na comparação ano a ano de matrizes estimadas, como as utilizadas neste estudo. Por sua vez, as parcelas da decomposição referentes aos termos de interação ( $\Delta$ Interac. Produtividade, $\Delta$ Interac. coeficientes de emprego, $\Delta$ Interac. mudança tecnológica e $\Delta$ Interac. Global) também tiveram um baixo impacto na mudança ocupacional total, o que não surpreende, uma vez que são calculadas como resíduos da variação total.

A variação no número de jovens que participam da força de trabalho ( $\Delta$ Partic.) segue padrões semelhantes à variação da ocupação juvenil, exceto entre 2008 e 2009, quando houve uma redução de 496,26 mil postos de trabalho e um aumento de 60,22 mil jovens na força de trabalho. No período, estima-se que cerca de 3.749,26 mil desses trabalhadores saíram do mercado de trabalho, resultando em um aumento de 547,37 mil jovens desocupados ( $\Delta$ Desoc.). Novamente, vale destacar que a redução no número de jovens na força de trabalho reflete a implementação de um conjunto de políticas públicas no período que permitiram o adiamento da entrada desses indivíduos na força de trabalho (Santos e Gimenez, 2015). 
O aumento na desocupação juvenil foi impulsionado pelas variações negativas dessa variável nos anos de 2005, 2009, 2014 e 2015. Nos demais anos, houve redução da desocupação. Em 2015, em particular, houve um aumento substancial no desemprego desses indivíduos, corroborando a premissa apontada pela literatura de que as flutuações na demanda agregada afetam, em grande medida, o desemprego juvenil.

A Tabela 2 apresenta os principais resultados setoriais ${ }^{10}$. No período, a maioria dos setores teve uma perda de empregos para trabalhadores jovens. Os setores que mais contribuíram para esse movimento foram Serviços domésticos (S43), Agricultura, silvicultura e exploração florestal (S1) e Pecuária e pesca (S2), com redução em relação ao total de 28,22\%, 26,11\% e 22,42\%, respectivamente, e somando uma perda de 3.297,76 mil postos de trabalho. Os respectivos setores representaram juntos cerca de $20,37 \%$ do total de empregos de jovens no período, o que ajuda a explicar a importância de tais segmentos na variação total.

Os Serviços domésticos (S43), que tiverem um declínio de 1.212,69 mil postos de trabalho juvenis, foram afetados, sobretudo, pelo componente de participação relativa ( $\Delta$ Participação relativa). Essa parcela, isoladamente, foi responsável pela perda de 1.041,37 mil postos de trabalho. Portanto, houve uma considerável perda de participação relativa de jovens nesse segmento. O consumo das famílias ( $\Delta$ Consumo das famílias), por sua vez, exerceu um efeito positivo, gerando cerca de 388,89 mil vagas.

A Agricultura, silvicultura e exploração florestal (S1) foi responsável pela queda de 1.121,69 mil empregos. Os principais fatores explicativos foram as mudanças na participação relativa dos jovens ( $\Delta$ Participação relativa) e as mudanças na produtividade do trabalho ( $\Delta$ Produtividade do trabalho). O consumo das famílias ( $\Delta$ Consumo das famílias) e as exportações ( $\Delta$ Exportações), por outro lado, tiveram um efeito positivo na geração de empregos. Como parte relevante da produção de tal segmento se destina ao mercado internacional, os resultados indicam que o crescimento das exportações favoreceu o aumento dessa produção, repercutindo na criação de empregos para os jovens.

O setor de Educação mercantil (S40) foi o que mais criou empregos no período, com um aumento de 178,67 mil postos de trabalho. O resultado positivo se deve, essencialmente, a um declínio na produtividade geral do trabalho ( $\Delta$ Produtividade do trabalho) e ao crescimento no consumo das famílias ( $\Delta$ Consumo das famílias) por esse serviço. Somados, os dois efeitos geraram cerca de 309.066 empregos.

\footnotetext{
${ }^{10}$ Os setores estão descritos no Quadro Al do Apêndice.
} 


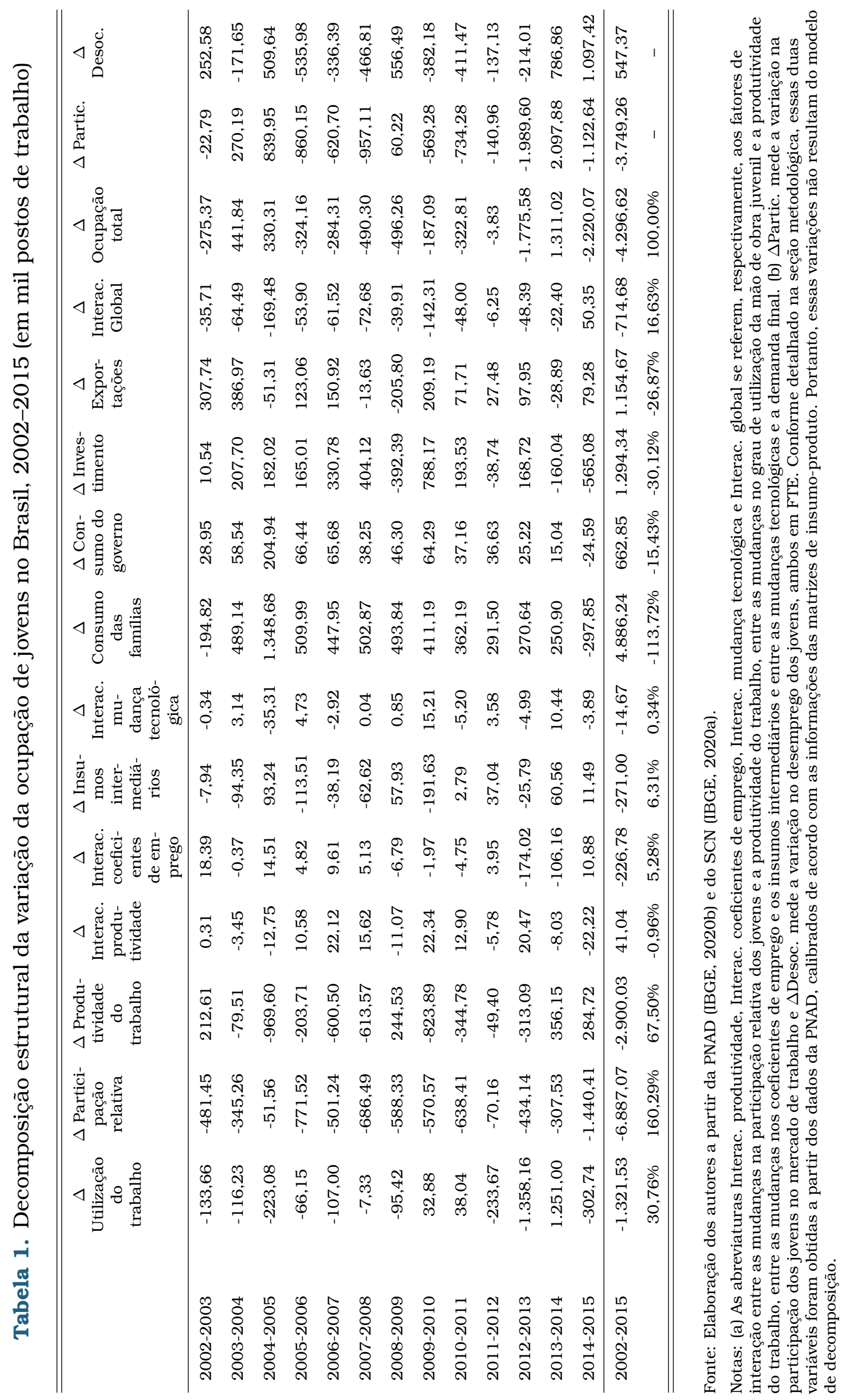




\begin{tabular}{|c|c|c|}
\hline 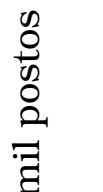 & & 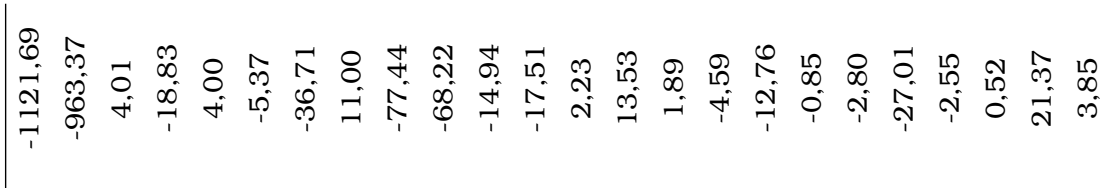 \\
\hline & 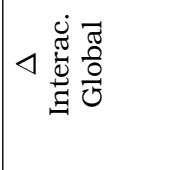 & 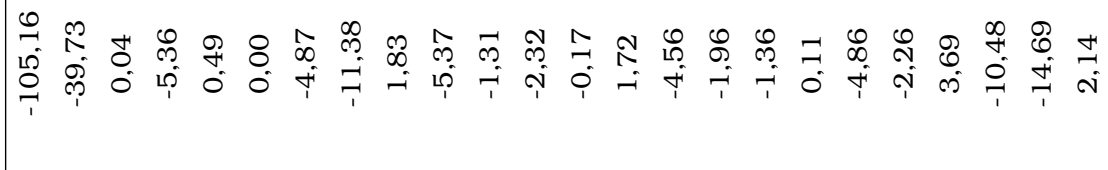 \\
\hline & 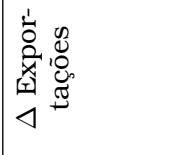 & 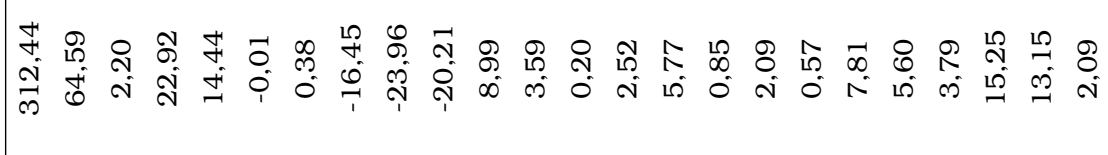 \\
\hline & 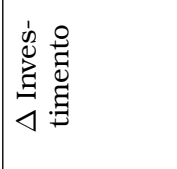 & 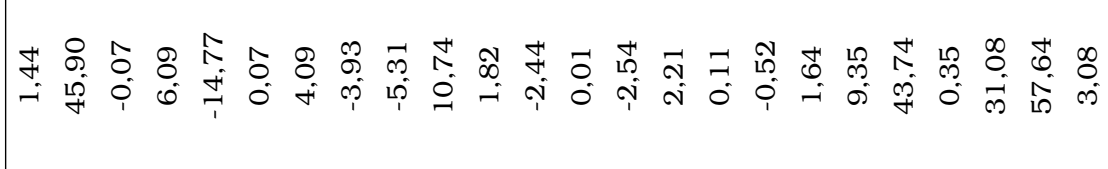 \\
\hline & 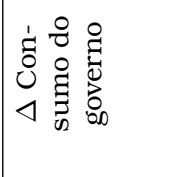 & 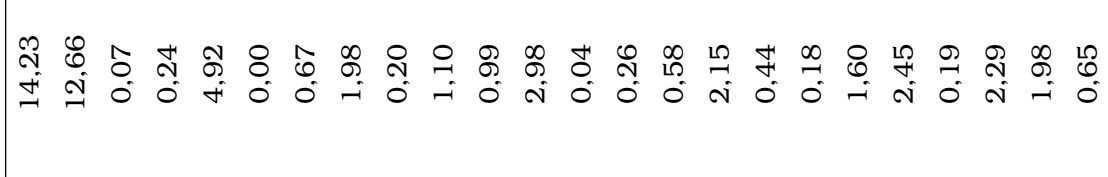 \\
\hline 离 & 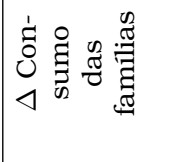 & 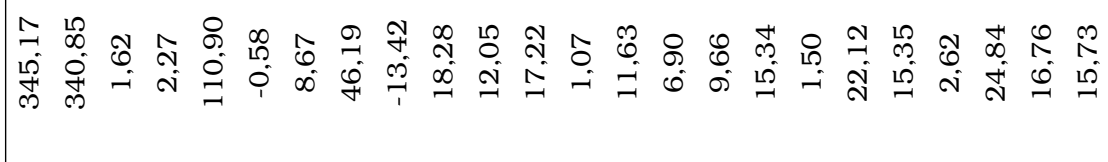 \\
\hline 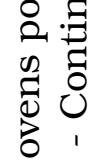 & 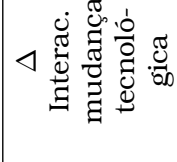 & 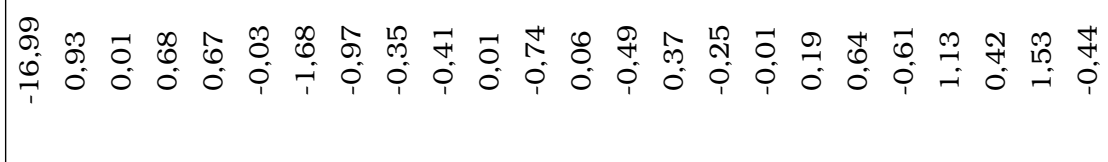 \\
\hline 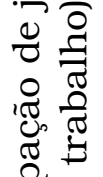 & 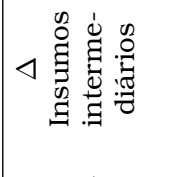 & 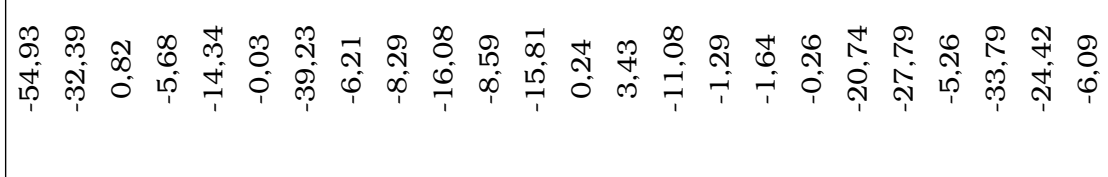 \\
\hline$\frac{1}{2}$ & 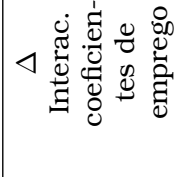 & 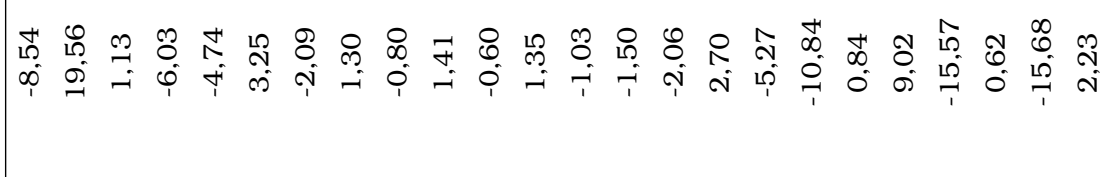 \\
\hline & 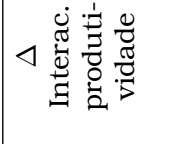 & 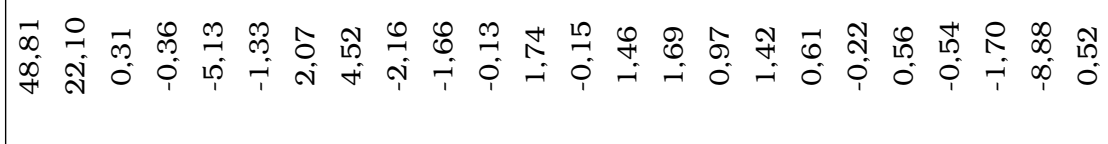 \\
\hline & 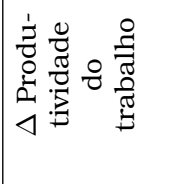 & 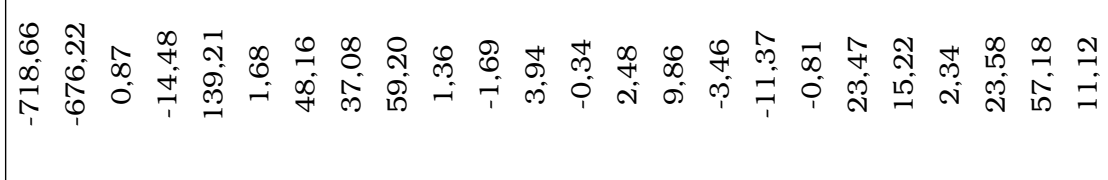 \\
\hline & 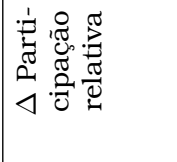 & 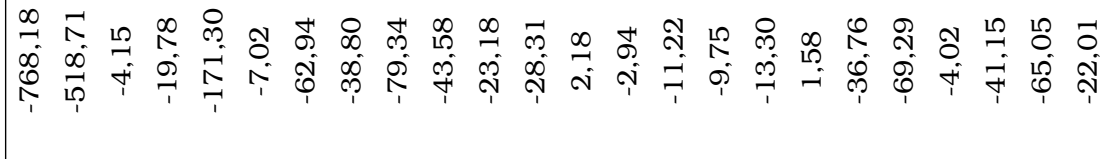 \\
\hline ह & 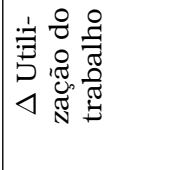 & 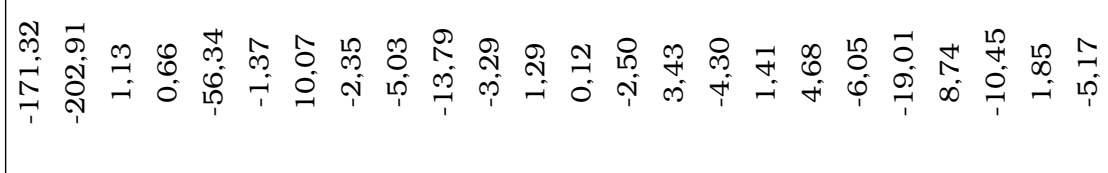 \\
\hline & & 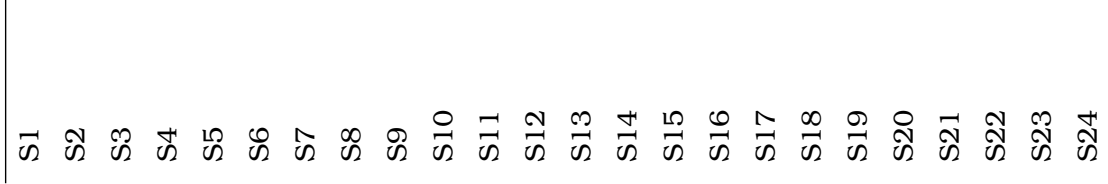 \\
\hline
\end{tabular}




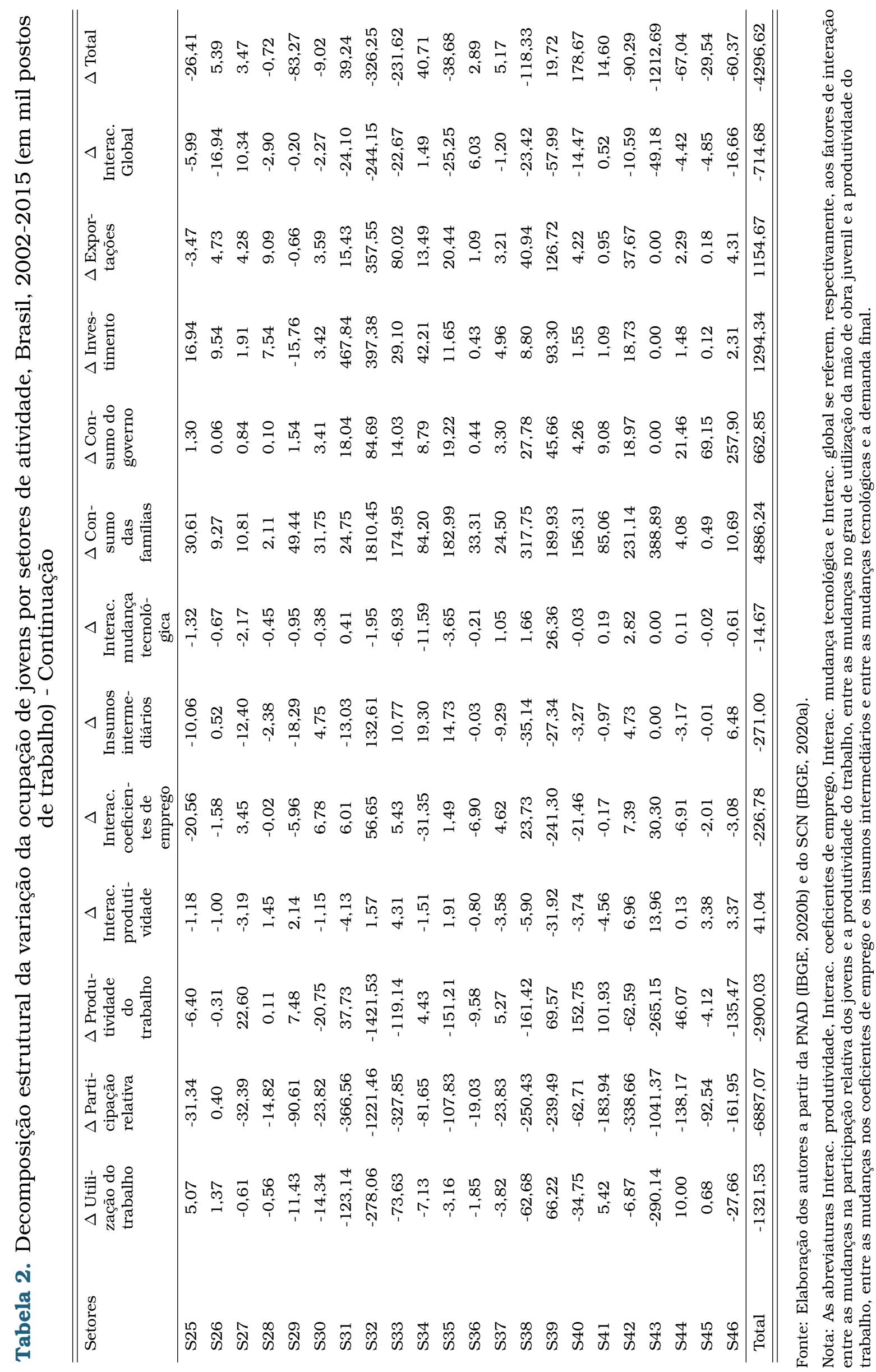


De modo geral, vale destacar alguns resultados. Primeiramente, as mudanças nos componentes dos coeficientes de emprego e na demanda final foram os principais determinantes da variação ocupacional dos jovens brasileiros. Enquanto a segunda categoria é pró-cíclica, a primeira não tem uma relação clara com os movimentos da atividade econômica. Além disso, as variações positivas na demanda final foram responsáveis pela maior parte dos empregos gerados no período, enquanto as mudanças nos coeficientes de emprego contribuíram negativamente. Este último quase sempre teve um impacto maior que a demanda final, explicando a redução do emprego dos jovens na maioria dos anos.

Outro fato é que, entre 2014 e 2015, em plena recessão econômica, houve a maior redução de empregos de jovens no período. Os resultados indicam que a maioria dos componentes da demanda final sofreram os impactos da crise e reduziram seu contingente de trabalhadores jovens. Por outro lado, entre 2013 e 2014, houve o maior acréscimo de empregos juvenis, refletindo as contribuições positivas dos coeficientes de emprego e da demanda final. Desse modo, apesar da importância da demanda agregada para explicar as variações ocupacionais dos jovens, as condições do mercado de trabalho, refletidas nos coeficientes de emprego, mostraram-se mais importantes.

Ademais, a redução na participação relativa dos jovens no emprego total, acompanhada da queda no número de empregos para esse grupo, enfraquece o argumento de que o declínio na participação juvenil no mercado de trabalho reduz seu desemprego, como é apontado em alguns trabalhos (Freeman e Wise, 1982; Biavaschi et al., 2012).

Também, destaca-se o aumento relativo de trabalhadores que estão trabalhando em período parcial. Tal movimento, ao ocorrer em um período de crescimento econômico, pode estar relacionado com a escolha dos próprios jovens em conciliar os estudos com as atividades ocupacionais. Segundo Pontes et al. (2018), as mudanças na economia brasileira durante esses anos fizeram com que o mercado exigisse maiores qualificações dos trabalhadores, o que repercutiu na oferta de trabalho dos jovens e na escolha em aperfeiçoar seu capital humano. Ao mesmo tempo, com o aumento da renda das famílias, alguns jovens que antes teriam que buscar emprego para complementar a renda familiar, passaram a se dedicar aos estudos. Ainda, cabe destacar os possiveis impactos da Lei do Aprendiz, regulamentada em 2005, sobre a jornada de trabalho de jovens e adolescentes. Como pontuam Shirasu e Arraes (2019), essa lei facilitou a entrada de muitos desses indivíduos no mercado de trabalho, possibilitando a aprendizagem remunerada com baixa carga horária.

Vale ressaltar que as mudanças na ocupação e na participação dos jovens na força de trabalho seguiram padrões semelhantes, sugerindo que uma parcela da variação ocupacional está relacionada às decisões desses indivíduos em entrar no mercado de trabalho. Contudo, uma discussão mais aprofundada dessa questão ultrapassa o escopo do estudo ao abranger características referentes à oferta de trabalho.

Por último, o efeito, comparativamente, pequeno das mudanças nos insumos in- 
termediários na variação total de empregos para os jovens está de acordo com outros estudos que comprovam a menor importância do fator tecnológico para a criação de empregos no Brasil (Sesso Filho et al., 2010; Nakatani-Macedo et al., 2015). Nos setores de agricultura e pecuária, indústria têxtil, indústria de cimento e alguns serviços, o avanço da tecnologia teve um considerável papel na redução dos postos de trabalho para tal grupo. No comércio e no segmento de serviços de informação, por outro lado, o referido componente contribuiu com a geração de vagas de trabalho.

As evidências discutidas revelam que o planejamento de políticas públicas deve considerar os aspectos individuais dos trabalhadores e as diferenças setoriais, pois o funcionamento do mercado de trabalho brasileiro é heterogêneo. Consequentemente, uma mesma política pode resultar em diferentes efeitos dependendo das características dos trabalhadores, das decisões das firmas e da conjuntura em que for adotada.

\section{Considerações finais}

O presente estudo decompôs a variação do emprego dos jovens brasileiros entre 2002 e 2015, pelo método de decomposição estrutural do emprego a partir das matrizes de insumo-produto para o período. Nesse contexto, a variação da ocupação juvenil foi explicada por fatores relacionados a mudanças nos insumos intermediários, nos coeficientes de emprego e nos componentes da demanda final.

Verificou-se que houve uma queda de 4,30 milhões de empregos, em termos de FTE, para esse grupo no período. O principal fator explicativo desse movimento foi a perda de participação relativa dos jovens no emprego total. O aumento na produtividade geral do trabalho também exerceu impacto negativo na variação do emprego desses indivíduos, sugerindo que a elevação na produtividade reduziu a demanda de trabalho. De igual modo, o declínio no grau de utilização da mão de obra juvenil teve efeito negativo na variação ocupacional, o que foi explicado pelo crescimento relativo de trabalhos em tempo parcial para esse grupo.

Quanto à demanda final, as mudanças nos seus componentes contribuíram positivamente para a variação do emprego juvenil, pois, durante o período, houve crescimento da atividade econômica. Em especial, o avanço no consumo das famílias foi responsável pela maior parte da criação de vagas de trabalho para os jovens, seguido por investimento, exportações e consumo do governo. As variações nos insumos intermediários tiveram uma contribuição negativa e pouco expressiva, uma vez que as mudanças tecnológicas tendem a variar menos no tempo.

Com relação aos resultados setoriais, a maioria dos setores teve uma perda de empregos para esses trabalhadores. Os setores que mais contribuíram para a referida queda foram os serviços domésticos, a agricultura, silvicultura e exploração florestal e a pecuária e pesca. Os fatores explicativos foram, principalmente, a perda de participação dos jovens no emprego total e o aumento na produtividade do trabalho. O setor de educação mercantil se caracterizou como o segmento que mais criou em- 
pregos devido, essencialmente, a um declínio na produtividade geral do trabalho e ao crescimento no consumo.

As evidências discutidas sugerem algumas medidas de políticas públicas a serem adotadas. A perda de participação relativa de jovens no emprego total indica a necessidade de políticas de emprego focadas na equalização das características produtivas entre as diferentes faixas etárias. Para isso, deve-se garantir o acesso à educação e a programas de treinamento, além de facilitar a transição dos jovens para o mercado de trabalho de modo a adequar seu perfil produtivo às necessidades do mercado.

Ademais, parte da redução de empregos entre os jovens se deveu ao aumento na produtividade do trabalho e, consequentemente, a uma redução geral na demanda de mão de obra. Uma vez que os aumentos de produtividade são desejáveis do ponto de vista macroeconômico, as formas de contrabalancear a queda na demanda provocada por esses aumentos estão relacionadas à expansão geral na atividade econômica e à qualificação profissional. No primeiro caso, com expansão geral da atividade econômica, a quantidade de postos de trabalho poupados tende a ser inferior à quantidade de novos postos de trabalho, enquanto o aumento do nível de qualificação profissional tende a aumentar a estabilidade do emprego.

Além de focar em grupos específicos, as políticas governamentais devem se ater às especificidades setoriais. Assim, é importante garantir o acesso dos jovens a segmentos que possuem postos de trabalho de maior qualidade. Os setores de saúde pública, educação pública e administração pública, por exemplo, caracterizam-se por alta estabilidade e maiores salários, contudo, são pouco representativos entre os jovens. A criação de postos de trabalho nesses segmentos direcionados, especificamente, aos jovens é uma alternativa. Por fim, nota-se que os empregos juvenis são afetados pelas flutuações econômicas. Portanto, além do planejamento apropriado das políticas discutidas, políticas de estabilização também são importantes.

Ademais, a perda de participação de jovens no emprego total pode estar associada a fatores culturais, discriminatórios e institucionais, que não foram diretamente capturados com a metodologia proposta. Isso sugere uma limitação da SDA, uma vez que essa depende das informações das contas nacionais, excluindo outros aspectos relevantes. Além disso, essa abordagem enfatiza características da demanda de trabalho, ignorando elementos inerentes à oferta, como mudanças nas alocações intrafamiliares da oferta de trabalho, permitindo que os jovens se dediquem por mais tempo aos estudos e entrem mais tarde no mercado de trabalho em períodos de aumento da renda. Nesse sentido, sugere-se que pesquisas futuras avaliem a questão do desemprego juvenil brasileiro considerando não apenas as relações intersetoriais da economia, mas também fatores inter-relacionados de oferta e demanda por trabalho. É importante ressaltar que o método de decomposição utilizado teve por objetivo analisar as mudanças no emprego juvenil. Isto posto, outra prioridade para pesquisas futuras será abordar diferentes dimensões do mercado de trabalho brasileiro, como os salários, os rendimentos e as horas trabalhadas desse grupo demográfico. 


\section{Referências}

Anyanwu, J. C. (2013). Characteristics and macroeconomic determinants of youth employment in Africa. African Development Review, 25(2):107-129.

Araújo, J. P. F. e Antigo, M. F. (2016). Desemprego e qualificação da mão de obra no Brasil. Revista de Economia Contemporânea, 20(1):308-335.

Artner, A. (2013). Is youth unemployment really the major worry? Debatte: Journal of Contemporary Central and Eastern Europe, 21(2-3):183-205.

Arto, I. e Dietzenbacher, E. (2014). Drivers of the growth in global greenhouse gas emissions. Environmental Science \& Technology, 48(10):5388-5394.

Baltar, P. e Leone, E. (2015). Perspectivas para o mercado de trabalho após o crescimento com inclusão social. Estudos Avançados, 29(85):53-67.

Banerji, A., Saksonovs, S., Huidan, L., e Blavy, R. (2014). Youth unemployment in advanced economies in Europe: searching for solutions, Washington DC: International Monetary Fund. (Discussion Paper).

Barakat, B., Holler, J., Prettner, K., e Schuster, J. (2010). The impact of the economic crisis on labour and education in Europe, Vienna Institute of Demography. (Working Paper, n. 6).

Bayrak, R. e Tatli, H. (2018). The determinants of youth unemployment: A panel data analysis of OECD countries. The European Journal of Comparative Economics, 15(2):231-248.

Bell, D. N. F. e Blanchflower, D. G. (2011). Young people and the Great Recession. Oxford Review of Economic Policy, 27(2):241-267.

Bertola, G., Driffill, J., James, H., Sinn, H., Sturm, J., e Valentinyi, A. (2013). Labour market reform and youth unemployment. In: Bertola, G.; Driffill, J.; James, H.; Sinn, H.; Sturm, J.; Valentinyi, Á. (Org). EEAG Report on the European Economy. Munich: CESifo, p. 73-94.

Biavaschi, C., Eichhorst, W., Giulietti, C., Kendzia, M., Muravyev, A., Pieters, J., Rodríguez-Planas, N., Schmidl, R., e Zimmermann, K. F. (2012). Youth unemployment and vocational training, Institute of Labor Economics, Bonn. (Discussion Paper, n. 6890).

Blair, P. e Wyckoff, A. (1989). The changing structure of the U.S. economy: an inputoutput analysis. In: Miller, R. E.; Polenske, K. R.; Rose, A. Z. (Ed.). Frontiers of input-output analysis. New York/London: Oxford University Press.

Blanchflower, D. G. e Freeman, R. B. (1996). Growing into Work, Centre for Economic Performance, The London School of Economics, London. (Working Paper, n. 108). 
Bredemeier, C. e Winklerp, R. (2017). The employment dynamics of different population groups over the business cycle. Applied Economics, 49(26):2545-2562.

Broecke, S. e Vandeweyer, M. (2016). Doubling the minimum wage and its effeects on labour market outcomes: evidence from Brazil, (Working Paper).

Campos, A., Corseuil, C. H., Foguel, M. N., e H, Z. (2017). Instituições trabalhistas e produtividade do trabalho: uma análise do caso brasileiro, Rio de Janeiro, RJ: IPEA. (Texto para Discussão, n. 2330).

Carter, A. P. (1970). Structural change in the American economy. Cambridge: Harvard University Press.

Cho, Y. e Newhouse, D. (2013). How did the great recession affect different types of workers? Evidence from 17 middle-income countries. World Development, 41(1):3150.

Choudhry, M. T., Marelli, E., e Signorelli, M. (2012). Youth unemployment rate and impact of financial crises. International Journal of Manpower, 33(1):76-95.

Clark, K. B. e Summers, L. H. (1978). Labor force transitions and unemployment, National Bureau of Economic Research, p. 1-37. (Working Paper, n. 277).

Clark, K. B. e Summers, L. H. (1982). The dynamics of youth unemployment. In: Freeman, R. B.; Wise, D. A. (Org). The youth labor market problem: its nature, causes, and consequences. Chicago: University of Chicago Press, p. 199-234.

Corseuil, C. H., Foguel, F., Gonzaga, G., e Ribeiro, E. P. (2013). A Rotatividade dos jovens no mercado de trabalho formal brasileiro. Conjuntura e Análise, Brasília, 55:157-173.

Corseuil, C. H. L. e Foguel, M. (2012). Economic expansion and increase in labour market formality: a poaching approach. Revista Brasileira de Economia, 66(1):207224.

Corseuil, C. H. L. e Franca, M. A. P. (2015). Inserção dos jovens no mercado de trabalho brasileiro: evolução e desigualdades no periodo 2006-2013. Brasília: Organização Internacional do Trabalho.

Corseuil, C. H. L., Franca, M. P., e Poloponsky, K. (2020). A inserção dos jovens brasileiros no mercado de trabalho num contexto de recessão. Novos Estudos, 39(1):501520 .

Cunha, D. A., Araújo, A. A., e Lima, J. E. (2011). Determinantes do desemprego e inatividade de jovens no Brasil metropolitano. Revista de Economia e Agronegócio, 9(3):369-392.

Dedecca, C. S. e Lopreato, F. L. C. (2013). Brasil: perspectivas do crescimento e desafios do mercado de trabalho, Campinas, SP: Instituto de Economia Unicamp. (Texto para Discussão, n. 225). 
Dietrich, H. (2013). Youth unemployment in the period 2001-2010 and the European crisis-looking at the empirical evidence. European Review of Labour and Research, 19(3):305-324.

Dietzenbacher, E. e Los, B. (1998). Structural decomposition techniques: sense and sensitivity. Economic Systems Research, 10(4):307-324.

Durotoye, A. (2014). The Crisis of Youth Unemployment in the MINT Countries: Causes, Consequences and Corrections. European Journal of Business and Management, 6(2): 1-14.

Duryea, S., Lam, D., e Levison, D. (2007). Effects of economic shocks on children's employment and schooling in Brazil. Journal of Development Economics, 84(1):188214.

Fallon, P. R. e Lucas, R. E. B. (2002). The impact of financial crises on labor markets, household incomes, and poverty: A review of evidence. The World Bank Research Observer, 17(1):21-45.

Flori, P. (2005). Desemprego dos jovens no Brasil. Revista da ABET, 5(1):30-60.

Freeman, R. B. (1979). Why is there a youth labor market problem?, National Bureau of Economic Research. (Working Paper, n. 365).

Freeman, R. B. e Wise, D. A. (1982). The youth labor market problem: Its nature causes and consequences. In: Freeman, R. B.; Wise, D. A. (Org). The youth labor market problem: its nature, causes, and consequences. Chicago: University of Chicago Press, p. 1-16.

Garcia, M. F., Araújo, E. C., Araújo, E. L., e Faustino, I. A. (2012). A condição do jovem no mercado de trabalho brasileiro: uma análise comparativa entre o emprego e o primeiro emprego (1999-2009). Economia, 13(3):481-506.

Giambiagi, F., Castro, L. B., Villela, A. A., e Hermann, J. (2016). Economia brasileira contemporânea (1945-2015). 3. ed. Rio de Janeiro: Elsevier.

Gorry, A. (2013). Minimum wages and youth unemployment. European Economic Review, 64(1):57-75.

Guilhoto, J. J. M. e Sesso Filho, U. A. (2005). Estimação da matriz insumo-produto a partir de dados preliminares das Contas Nacionais. Economia Aplicada, 9(2):277299.

Guilhoto, J. J. M. e Sesso Filho, U. A. (2010). Estimação da matriz insumo produto utilizando dados preliminares das Contas Nacionais: aplicação e análise de indicadores econômicos para o Brasil em 2005. Economia \& Tecnologia, 23(1):53-63.

Han, X. (1995). Structural change and labor requirement of the Japanese economy. Economic Systems Research, 7(1):47-66. 
Hoynes, H., Miller, D. L., e Schaller, J. (2012). Who suffers during recessions?. Journal of Economic Perspectives, 26(3):27-48.

IBGE (2015). Instituto Brasileiro de Geografia e Estatística. Retropolação de séries e Tabelas de Recursos e Usos. Sistema de Contas Nacionais - Brasil (SCN) - Referência 2010. Nota Metodológica n. 17.

IBGE (2018). Instituto Brasileiro de Geografia e Estatística. Síntese de Indicadores Sociais. Uma análise das condições de vida da população brasileir. Disponível em: <http://biblioteca.ibge.gov.br/visualizacao/livros/liv101459.pdf>. Acesso em: jul. 2020.

IBGE (2020a). Instituto Brasileiro de Geografia e Estatística. Sistema de Contas Nacionais. Rio de Janeiro. Disponivel em: <https://www.ibge.gov.br/estatisticas/economicas/contas-nacionais/9052sistema-de-contas-nacionais-brasil.html?=\&t=downloads $>$. Acesso em: jul. 2020.

IBGE (2020b). Instituto Brasileiro de Geografia e Estatística. Pesquisa Nacional por Amostra de Domicílios. Disponível em: <https://www.ibge.gov.br/estatisticas/sociais/populacao/9127-pesquisanacional-por-amostra-de-domicilios.html?=\&t=microdadoss $>$. Acesso em: jul. 2020.

Incera, A. C. (2017). Drivers of change in the European youth employment: a comparative structural decomposition analysis. Economic Systems Research, 29(4):463-485.

Jimeno, J. e Rodriguez-Palenzuela, D. (2002). Youth unemployment in the OECD: demographic shifts, labour market institutions and macroeconomic shocks, European Central Bank. (Working Paper, n. 155).

Justesen, M. (2008). Is the window of opportunity closing for Brazilian youth?, Labor market trends and business cycle effects. The World Bank. (Discussion Papers, n. 806).

Korenman, S. e Neumark, D. (2000). Cohort crowding and youth labor markets: A cross-national analysis, youth employment and joblessness in advanced countries, National Bureau of Economic Research, p. 57-106. (Working Paper, n. 6031).

Kupfer, D. e Freitas, F. (2004). Análise estrutural da variação do emprego no Brasil entre 1990 e 2001, Boletim de Conjuntura, Instituto de Economia, Rio de Janeiro.

Laporšek, S. (2013). Minimum wage effects on youth employment in the European Union. Applied Economics Letters, 20(14):1288-1292.

Leighton, L. e Mincer, J. (1982). Labor turnover and youth unemployment. In: Freeman, R. B.; Wise, D. A. (Org). The youth labor market problem: Its nature, causes, and consequences. Chicago: University of Chicago Press, p. 235-276. 
Miller, R. E. e Blair, P. D. (2009). Input output analysis: foundations and extensions. Prentice Hall.

Nakatani-Macedo, C. D., Fiuza-Moura, F. K., Câmara, M. G., e Sesso-Filho, U. A. (2015). Decomposição estrutural da variação do emprego nos setores industriais no Brasil entre os anos de 2000 e 2009. Revista de Economia Contemporânea, 19(2):127.

O'Higgins, N. (2001). Youth unemployment and employment policy: a global perspective. Munich Personal RePEc Archive. (Discussion Paper, n. 23698).

O'Higgins, N. (2012). This time it's different? Youth labour markets during "The Great Recession”. Comparative Economic Studies, 54(2):395-412.

Pochmann, M. (2018). Desempenho econômico conjuntural e a situação recente do trabalho no Brasil. Revista do Núcleo de Estudos de Economia Catarinense, 7(1):1228.

Pontes, R. P., Barbosa, M. N., Silveira, L. S., e Costa, L. V. (2018). O comportamento de jovens e adultos no mercado de trabalho brasileiro com relação à permanência no emprego. Revista de Economia Contemporânea, 22(3):1-23.

Rice, P. G. (1986). Juvenile unemployment, relative wages and social security in Great Britain. The Economic Journal, 96(3):352-374.

Santos, A. L. e Gimenez, D. M. (2015). Inserção dos jovens no mercado de trabalho. Estudos Avançados, 29(5):153-168.

Sesso Filho, U. A., Rodrigues, L. R., Moretto, A. C., Brene, P. R. A., e Lopes, R. L. (2010). Decomposição estrutural da variação do emprego no Brasil, 1991-2003. Economia Aplicada, 14(1):99-123.

Shimer, R. (1998). Why is the US unemployment rate so much lower?. National Bureau of Economic Research. Macroeconomics Annual, 13(1): 11-61.

Shirasu, M. R. e Arraes, R. A. (2019). Decisão dos jovens brasileiros: trabalhar e/ou estudar ou nem-nem. Pesquisa e Planejamento Econômico, 49(2):97-130.

Silva, N. D. V. e Kassouf, A. L. (2002). A exclusão social dos jovens no mercado de trabalho brasileiro. Revista Brasileira de Estudos de População, 19(2):99-115.

Skolka, J. (1989). Input-output structural decomposition analysis for Austria. In: Kurz, H. D.; Dietzebacher, E.; Lager, C. (Ed.). Input-output analysis. Cheltenham: Edward Elgar.

Souen, J. A. e Campos, G. C. S. (2017). Da euforia ao retrocesso: o comportamento do emprego formal no Brasil no período recente. Revista Pesquisa \& Debate, 28(1):4262. 
Sturn, S. (2017). Do minimum wages lead to job losses? Evidence from OECD countries on low-skilled and youth employment. ILR Review, 71(3):647-675.

Tomić, I. (2018). What drives youth unemployment in Europe? Economic vs noneconomic determinants. International Labour Review, 157(3):379-408.

Vale, V. A. e Perobelli, F. S. (2020). Análise de Insumo-Produto: teoria e aplicações no R. NEDUR/LATES. Curitiba, PR: Edição Independente.

Van der Gaag, N. e Beer, J. (2015). From Demographic Dividend to Demographic Burden: The Impact of Population Ageing on Economic Growth in Europe. Tijdschrift voor Economische en Sociale Geografie, 106(1):29-44.

Verick, S. (2009). Who is hit hardest during a financial crisis?, The vulnerability of young men and women to unemployment in an economic downturn. Institute of Labor Economics. (Discussion Papers, n. 4359).

(ब) Es 


\section{Apêndices}

Tabela A1. Correspondência entre os setores finais e os setores do SCN

\begin{tabular}{|c|c|c|}
\hline Abreviaturas & Setores finais & Setores do SCN \\
\hline S1 & Agricultura, silvicultura e exploração florestal & 1 \\
\hline $\mathrm{S} 2$ & Pecuária e pesca & 2 \\
\hline S3 & Petróleo e gás natural & 3 \\
\hline $\mathrm{S} 4$ & Outros da indústria extrativa & $4-5$ \\
\hline S5 & Alimentos e Bebidas & 6 \\
\hline S6 & Produtos do fumo & 7 \\
\hline S7 & Têxteis & 8 \\
\hline S8 & Artigos do vestuário e acessórios & 9 \\
\hline S9 & Artefatos de couro e calçados & 10 \\
\hline $\mathrm{S} 10$ & Produtos de madeira - exclusive móveis & 11 \\
\hline $\mathrm{S} 11$ & Celulose e produtos de papel & 12 \\
\hline $\mathrm{S} 12$ & Jornais revistas discos & 13 \\
\hline $\mathrm{S} 13$ & Refino de petróleo e coque & 14 \\
\hline $\mathrm{S} 14$ & Álcool & 15 \\
\hline S15 & Produtos químicos & $16-17 ; 19 ; 22$ \\
\hline S16 & Produtos farmacêuticos & 18 \\
\hline $\mathrm{S} 17$ & Perfumaria higiene e limpeza & 20 \\
\hline $\mathrm{S} 18$ & Tintas vernizes esmaltes e lacas & 21 \\
\hline S19 & Artigos de borracha e plástico & 23 \\
\hline $\mathrm{S} 20$ & Cimento e outros produtos de minerais não-metálicos & 24 \\
\hline $\mathrm{S} 21$ & Metalurgia de metais não-ferrosos & 26 \\
\hline $\mathrm{S} 22$ & Produtos de metal - exclusive máquinas e equipamentos & $25-27$ \\
\hline $\mathrm{S} 23$ & Máquinas e equipamentos, manutenção e reparos & 28 \\
\hline S24 & Eletrodomésticos e material elétrico & 29 \\
\hline S25 & Máquinas para escritório, aparelhos e material eletrônico & 30 \\
\hline S26 & Automóveis, camionetas, caminhões e ônibus & 31 \\
\hline S27 & Peças e acessórios para veículos automotores & 32 \\
\hline $\mathrm{S} 28$ & Outros equipamentos de transporte & 33 \\
\hline S29 & Móveis e produtos das indústrias diversas & 34 \\
\hline S30 & Eletricidade e gás, água, esgoto e limpeza urbana & 35 \\
\hline S31 & Construção civil & 36 \\
\hline S32 & Comércio & 37 \\
\hline S33 & Transporte, armazenagem e correio & 38 \\
\hline S34 & Serviços de informação & 39 \\
\hline S35 & Intermediação financeira, seguros e previdência & 40 \\
\hline S36 & Atividades imobiliárias e aluguéis & 41 \\
\hline S37 & Serviços de manutenção e reparação & 42 \\
\hline S38 & Serviços de alojamento e alimentação & 43 \\
\hline S39 & Serviços prestados às empresas & 44 \\
\hline S40 & Educação mercantil & 45 \\
\hline S41 & Saúde mercantil & 46 \\
\hline S42 & Serviços prestados às famílias e associativas & 47 \\
\hline S43 & Serviços domésticos & 48 \\
\hline S44 & Educação pública & 49 \\
\hline S45 & Saúde pública & 50 \\
\hline S46 & Administração pública e seguridade social & 51 \\
\hline
\end{tabular}

Fonte: Elaboração dos autores, a partir do SCN (IBGE, 2020a).

Nota: Para códigos como 16-17, todos os setores neste intervalo foram incluídos. 
Tabela A2. Evolução do número de postos de trabalho de jovens e dos totais de jovens desocupados e na força de trabalho, em FTE, 2002-2015 (em mil)

\begin{tabular}{llcc}
\hline \hline Ano & Ocupação & Desocupação & $\begin{array}{c}\text { Total na } \\
\text { força de } \\
\text { trabalho }\end{array}$ \\
\hline 2002 & $18.924,67$ & $4.269,64$ & $23.194,31$ \\
2003 & $18.649,30$ & $4.522,22$ & $23.171,52$ \\
2004 & $19.091,14$ & $4.350,58$ & $23.441,72$ \\
2005 & $19.421,45$ & $4.860,22$ & $24.281,67$ \\
2006 & $19.097,28$ & $4.324,24$ & $23.421,52$ \\
2007 & $18.812,97$ & $3.987,85$ & $22.800,82$ \\
2008 & $18.322,67$ & $3.521,04$ & $21.843,70$ \\
2009 & $17.826,40$ & $4.077,52$ & $21.903,93$ \\
2010 & $17.639,31$ & $3.695,34$ & $21.334,65$ \\
2011 & $17.316,51$ & $3.283,87$ & $20.600,37$ \\
2012 & $17.312,68$ & $3.146,74$ & $20.459,42$ \\
2013 & $15.537,10$ & $2.932,73$ & $18.469,82$ \\
2014 & $16.848,11$ & $3.719,59$ & $20.567,70$ \\
2015 & $14.628,05$ & $4.817,01$ & $19.445,06$ \\
\hline \hline
\end{tabular}

Fonte: Elaboração dos autores, a partir da PNAD (IBGE, 2020b) e do SCN (IBGE, 2020a). 